MARIO CESAR MARQUES GEMAQUE VILHENA

\title{
A PROTEÇÃO DO CONHECIMENTO TRADICIONAL NO BRASIL E NA ÍNDIA
}

\author{
DISSERTAÇÃO DE MESTRADO
}

ORIENTADOR: Professor Doutor Dalmo de Abreu Dallari

UNIVERSIDADE DE SÃO PAULO - USP

FACULDADE DE DIREITO

SÃO PAULO 


\title{
A PROTEÇÃO DO CONHECIMENTO TRADICIONAL NO BRASIL E NA ÍNDIA
}

\author{
Dissertação de Mestrado apresentada à \\ Universidade de São Paulo - USP como \\ exigência parcial para obtenção do título de \\ Mestrado em Direito. \\ Orientador: Prof. Dalmo de Abreu Dallari
}

UNIVERSIDADE DE SÃO PAULO - USP

FACULDADE DE DIREITO

SÃO PAULO

2019 


\title{
A PROTEÇÃO DO CONHECIMENTO TRADICIONAL NO BRASIL E NA ÍNDIA
}

\author{
Dissertação de Mestrado apresentada à \\ Universidade de São Paulo - USP como \\ exigência parcial para obtenção do título de \\ Mestrado em Direito. \\ Área de concentração: Direitos Humanos
}

Data de aprovação:

MEMBROS COMPONENTES DA BANCA EXAMINADORA:

Prof.

Instituição de Ensino

Prof.

Instituição de Ensino

Prof.

Instituição de Ensino

Local: São Paulo, SP, Universidade de São Paulo - USP 


\section{EPÍGRAFE}

"Era um sonho dantesco... o tombadilho, Tinir de ferros... estalar do açoite... Legiões de homens negros como a noite, horrendos a dançar... Senhor Deus dos desgraçados! Dizeime vós, Senhor Deus! Se é loucura... se é verdade Tanto horror perante os céus... Ó mar, por que não apagas de tuas vagas De teu manto este borrão? Astros! noite! tempestades! Rolai das imensidades! Varrei os mares, tufão!... E existe um povo que a bandeira empresta P'ra cobrir tanta infâmia e covardia!... E deixa-a transformar-se nessa festa Em manto impuro de bacante fria!... Meu Deus! Meu Deus! Mas que bandeira é esta, Que impudente na gávea tripudia?!... Auriverde pendão de minha terra, Que a brisa do Brasil beija e balança, Antes te houvessem roto na batalha, Que servires a um povo de mortalha!... Mas é infâmia demais... Da etérea plaga Levantai-vos, heróis do Novo Mundo... Andrada! Arranca este pendão dos ares! Colombo! fecha a porta de teus mares!" Castro Alves 


\section{RESUMO}

Este trabalho aborda a questão da proteção do conhecimento tradicional dos povos indígenas no Brasil e Adivasis na Índia, a distinção do conhecimento tradicional e do conhecimento científico. Partimos do debate que surge a partir da expansão colonial européia nas Américas e na Ásia que tornam o conhecimento tradicional periférico. Os grupos indígenas e comunidades tradicionais vivem em estreita interação com seu ambiente natural. Baseados em experiências seculares, eles aprenderam como fazer uso da biodiversidade local, a fim de lidar com as necessidades diárias. Nos casos aqui analisados, suas experiências são incorporadas em um contexto de práticas socioculturais complexas que estão intimamente associadas com a cosmologia, convicções epistemológicas e transcendentais. Leis costumeiras regulamentam o acesso, transmissão e difusão do conhecimento dentro das comunidades Tradicionais. Verificamos casos em que comunidades locais tentam manter seu conhecimento em segredo, uma vez que o consideram sagrado e, portanto, inalienável. Verificamos ainda, outros casos, em que não permitem ma exploração comercial de seus conhecimentos, devido ao seu significado espiritual. Geralmente, indígenas e comunidades locais insistem em seu direito de decidir por si mesmos e estabelecem as condições sob as quais, se for o caso, eles estão dispostos a divulgar seu conhecimento. Este trabalho tem o objetivo de abordar a proteção do conhecimento tradicional no Brasil e na Índia, tratando das comunidades locais e os mecanismos de proteção do conhecimento. Enfoca, ainda, o tratamento da questão nos fóruns internacionais como a Organização Mundial de Propriedade Intelectual - OMPI, e do Comércio OMC , além de outras legislações como a Convenção 169 da Organização Internacional do Trabalho - OIT e Convenção da Biodiversidade. Assim, a oposição entre o sistema de proteção de propriedade intelectual e proteção da Biodiversidade evidenciam a dificuldade e limitação do ordenamento jurídico e do sistema universal do direito para proteção do conhecimento tradicional no âmbito internacional e nos Estados do Brasil e da Índia.

Palavras-chave: Conhecimento Tradicional. Biodiversidade, Brasil. Índia. Proteção. 


\begin{abstract}
This manuscript addresses the issue of protection of traditional knowledge of indigenous peoples in Brazil and Adivasis in India, the distinction of traditional knowledge and scientific knowledge. We start from the debate that emerges from European colonial expansion in the Americas and Asia that make traditional knowledge peripheral. Indigenous groups and traditional communities live in close interaction with their natural environment. Based on secular experiences, they have learned how to make use of local animals and plants in order to handle their daily needs. In many cases, their experiences are embodied in a context of complex sociocultural practices that are intimately associated with cosmology, epistemological and transcendental convictions. Custom laws regulate the access, transmission and diffusion of knowledge within communities. In some cases, local communities try to keep certain elements of their knowledge a secret, since they consider it sacred and therefore inalienable. In other cases, they refuse to allow a commercial exploitation of their knowledge because of their spiritual significance. Generally, indigenous and local communities insist on their right to decide for themselves and establish the conditions under which, if any, they are willing to disseminate their knowledge. This work aims to address the protection of traditional knowledge in Brazil and India, dealing with local communities and knowledge protection mechanisms.

It also emphasizes the treatment of the issue in international fora such as the World Intellectual Property Organization (WIPO) and the World Trade Organization (WTO), as well as other legislation such as the Convention 169 International Labor Organizarion and the Biodiversity Convention. Thus, the opposition between the system of protection of intellectual property and protection of Biodiversity evidences the difficulty and limitation of the legal system and the universal system of protection of traditional knowledge in the international scope and in the States of Brazil and India.
\end{abstract}

Keywords: Traditional Knowledge, Brazil. Biodiversity, India. Protection. 


\section{LISTA DE SIGLAS}

ADPIC - Acordo Sobre Aspectos dos Direitos de Propriedade Intelectual Relacionados ao Comércio

ARB - Acesso e repartição de benefícios

CDB - Convenção sobre Diversidade Biológica

CGRFA - Comissão de Recursos Genéticos para Alimentação e Agricultura

COP - Organização comunitária baseada na Conferência das Partes

CPI - Consentimento prévio informado

CT - Conhecimento tradicional

CTs - Conhecimentos Tadicionais

DPI - Direitos de Propriedade Intelectual

DPI - Direitos de propriedade intelectual

FAO - Organização das Nações Unidas para a Alimentação e a Agricultura

GATT - Acordo Geral sobre Tarifas e Comércio

IG - Indicação geográfica

IP - Propriedade intelectual

MAFW

OIT - Organização Internacional do Trabalho (OIT) IP

OMC - Organização Mundial do Comércio

OMPI - Organização Mundial da Propriedade Intelectual

OMS - Organização Mundial da Saúde

ONG - Organização não governamental

PIB - Produto Interno Bruto

PNB - Produto nacional bruto

PNUD - Programa das Nações Unidas para o Desenvolvimento

PNUMA - Programa das Nações Unidas para o Meio Ambiente

TI - Terras Indígenas

TKDL - Sigla em inglês para designar a Biblioteca Digital de Conhecimento Tradicional (TKDL).

TRIPS - Acordo sobre os Aspectos dos Direitos de Propriedade Intelectual Relacionados ao Comércio ONU - Organização das Nações Unidas

UNCED - Conferência das Nações Unidas sobre Meio Ambiente e Desenvolvimento

UNCTAD - Conferência das Nações Unidas sobre Comércio e Desenvolvimento UPOV - União Internacional para a Proteção de Novas Variedades de Plantas 
LISTA DE FIGURAS

FIGURA

13

2 


\section{SUMÁRIO}

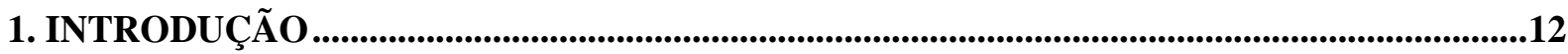

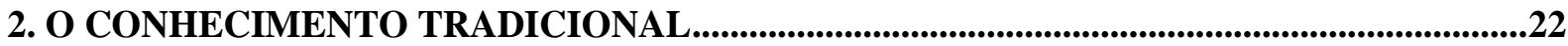

2.1 A Importância do Conhecimento Tradicional..........................................................................................................22

2.2 Diversidades Epistemológicas e Produção do Conhecimento ...........................................................23

2.3 A modernidade e o eurocentrismo: crítica à universalidade etnocêntrica..................................................24

2.3.1 A formação e ascensão da ciência moderna como conhecimento universal ...........................................24

2.3.1.1 Pensamento pós-colonial Latino Americano e Orientalista..........................................32

2.3.2 A identidade do "Outro" colonizado à luz das reflexões dos estudos Pós-Coloniais Orientalistas................36

2.4 A Construção do Tradicional como um Conhecimento do Outro ............................................................44

2.5 Conclusões do capítulo: conceitos do conhecimento tradicional ................................................................56

3. BREVE HISTÓRICO DOS CONHECIMENTOS TRADICIONAIS NO CENÁRIO

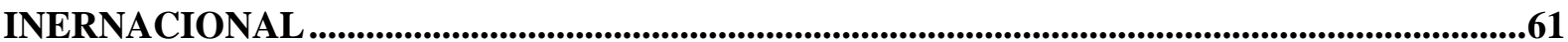

3.1. A Construção do Sujeito Internacional do Direito de Proteção ao Conhecimento Tradicional .............62

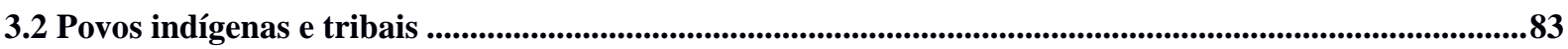

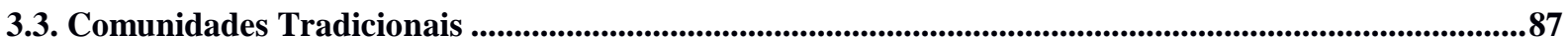

3.4 Sistema internacional de proteção do conhecimento tradicional e seus princípios ....................................89

3.5 A Convenção da biodiversidade e o Sistema de proteção da Propriedade Intelectual .............................89

3.6 Sistema da Organização Mundial de Propriedade Intelectual ................................................................90

3.7 Direitos de propriedade intelectual e recursos da biodiversidade ...................................................................96

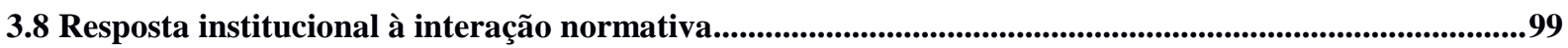

3.9 Respostas políticas adequadas para reduzir ou evitar efeitos perturbadores? ........................................102

3.10 Marco Internacional da Biodiversidade - A Convenção da Biodiversidade ...........................................103

3.11 O contexto da internacionalização da proteção à Biodiversidade ...........................................................107

3.12 Construção histórica da convenção da biodiversidade .................................................................................111

4. O ESTADO INDIANO E OS CONHECIMENTOS TRADICIONAIS ................................113

4.1 Conhecimento tradicional como riqueza nacional na Índia ........................................................117

4.2 Adivasis...............................................................................................................................................................................123

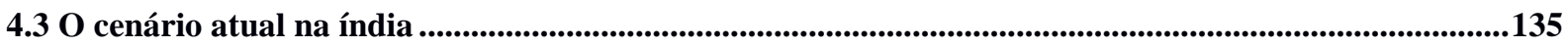

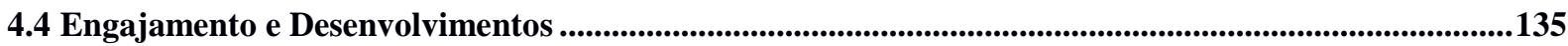

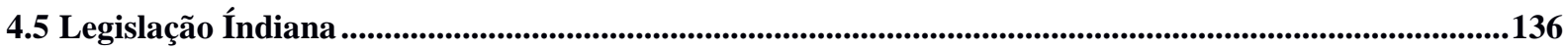

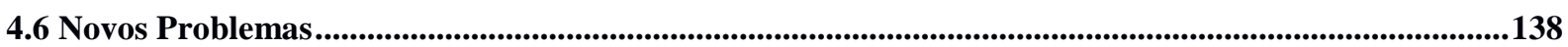

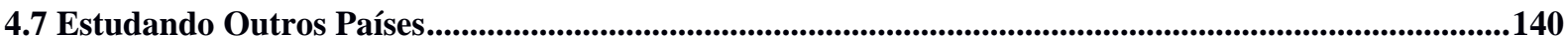

4.8 Convenção global sobre diversidade biológica (CDB) e a lei de diversidade biológica indiana.

143

4. 9 Acesso aos recursos biológicos

5. O ESTADO BRASILEIRO E OS CONHECIMETNOS TRADICIONAIS .............................148

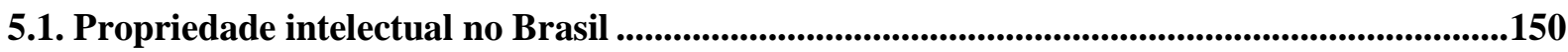


5.2. A exploração da biodiversidade e doconhecimento tradicional no brasil ................................154

5.3. Propriedade intelectual no Brasil ...........................................................................................................161

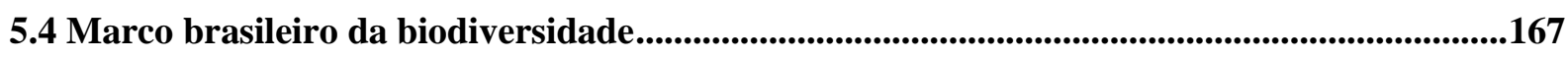

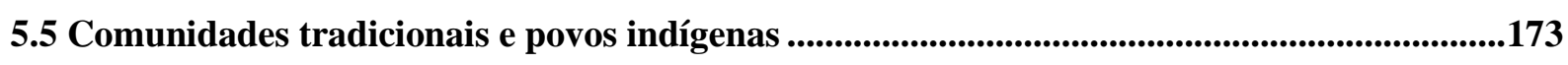

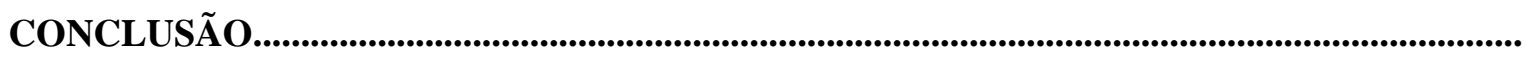

189

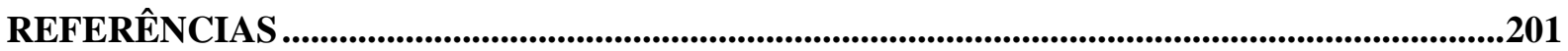




\section{INTRODUÇÃO}

Este trabalho estuda a proteção do conhecimento tradicional (CT) no Brasil e na Índia. Nos quatro capítulos que o compõem partiu-se de discussões acerca da importância do CT e sua conceituação em relação às outras gramáticas epistemológicas e do processo de colonização das Américas e da Ásia. Com isso, enfocou-se os meios de proteção do conhecimento tradicional nos níveis nacional, na Índia, no Brasil e no âmbito internacional. Nesta pesquisa estão relatados os esforços nestes Estados e em nível internacional para usar os instrumentos de Direito de Propriedade Intelectual - DPI existentes, bem como para desenvolver sistemas sui generis para a proteção dos Conhecimentos Tradicionais (CTs). A dimensão internacional da proteção dos CTs é abordada pelos muitos documentos elaborados pelos organismos e organizações internacionais que trabalham nesse campo e representantes da sociedade civil.

Em discussões sobre a proteção de Conhecimento Tradicional, cumpre ressaltar que o termo pode ser usado livremente para se referir a vários objetivos diferentes.

Assim, destaca-se uma série de razões pelas quais a proteção dos CTs é importante. Estes incluem a observância de políticas públicas para proteção das comunidades tradicionais, em especial as indígenas e Adivasis, detentores de Conhecimentos. A relação que o conhecimento tradicional tem com a economia nacional e conservação dos ecossistemas naturais (DUTFIELD, 2000; HAMWEY 2004; KAUSHIK et al, 2008). Hamwey enfatiza o importante papel que este objeto de estudo tem desempenhado na prevenção da degradação do solo, do esgotamento da pesca, da erosão da biodiversidade e do desmatamento.

A expropriação dos conhecimentos tradicionais e a iminente crise de extinção que afeta as diversas culturas e idiomas do mundo, $90 \%$ dos quais provavelmente desaparecerão nos próximos 100 anos $^{1}$. Eles também apontam a alta correlação entre diversidade cultural, linguística e biológica.

Vários autores identificam as causas fundamentais da erosão da CT em seus países. Estes incluem a adoção de modernas práticas agrícolas intensivas usando variedades de plantas híbridas de alto rendimento (Le Quy, Fenta, Guedes e Sampaio, Ahmed, Sahai), o deslocamento de comunidades devido à exploração madeireira e

\footnotetext{
${ }^{1}$ A Organização das Nações Unidas para a Educação, a Ciência e a Cultura - UNESCO, criou um atlas indicando diversos idiomas em risco de extinção no planeta. O banco de dados esta disponível no sitio eletrônico: http://www.unesco.org/languages-atlas/
} 
projetos de mineração (Blanco), modernização do sistema médico (Kumar) e diminuição do interesse da geração mais jovem (Sahai).

Muitos autores de artigos enfatizam que os CTs não podem ser adequadamente protegidos sob os atuais regimes convencionais de DPI (incluindo elementos como patentes, proteção de variedades de plantas, marcas registradas, projetos e direitos autorais). Esses regimes geralmente protegem os direitos de propriedade individual, enquanto a propriedade de CT é, em geral, coletiva. Como o conhecimento tradicional é desenvolvido ao longo do tempo e é codificado em textos antigos ou retido nas tradições orais ao longo de gerações, ele não possui os atributos de novidade e inovação, que são necessários para a concessão de patentes. Além disso, diferentes comunidades geralmente mantêm conhecimento similar.

Diversos especialistas ressaltam que o atual sistema de DPI é inadequado para o reconhecimento e proteção de CT por causa de conflitos inerentes entre esses dois sistemas (Grupos Indígenas, da Cunha, Ekpere, Salomão). Eles enfatizam as cosmovisões holísticas das comunidades indígenas e locais e enfatizam que dividi-las artificialmente em categorias legais separadas é inadequado e inaceitável. Nakashima adverte que os direitos de propriedade intelectual e a ciência podem levar à fragmentação dos sistemas CT.

Desde o início da era colonial, o conhecimento das comunidades indígenas relacionado à natureza tem atraído a atenção de cientistas e pesquisadores. Com base em observações e entrevistas, exploradores como Alexander von Humboldt "descobriu" novas espécies, que foram investigadas por pesquisadores nos jardins botânicos de suas terras natais.

Carl Linnaeus desenvolveu taxonomias zoológicas e botânicas baseadas nas percepções dos grupos indígenas (BRUSH, 1996). Esse tipo de transferência de conhecimento não regulamentada permaneceu em grande parte indiscutível. A interação entre as comunidades locais e os atores externos tomou o centro do palco de um debate internacional desde a década de 1980 (BASTOS, 2009).

Existem várias razões para uma maior atenção às tradicionais políticas de conhecimento. Em primeiro lugar, a pesquisa sobre o tema especialmente relacionado à biodiversidade intensificou dramaticamente desde que a ciência da vida e as agroindústrias começaram a usar bioexplorações como um meio para acelerar sua pesquisa sobre novos medicamentos e métodos de cultivo (DUTFIELD, 2011; PANDIKUMAR et al., 2011). 
Em segundo lugar, os grupos ambientalistas identificaram o conhecimento tradicional como uma ferramenta importante para preservar a biodiversidade. Cada vez mais, atividades conservacionistas estão relacionadas a esquemas de proteção climática, como o Mecanismo de Desenvolvimento Limpo (MDL) ou REDD (Redução de Emissões de desmatamento e degradação) (DEBBARMA, 2006).

Em terceiro lugar, os atores governamentais dos países em desenvolvimento percebem a diversidade de seus recursos naturais como um ativo econômico ("ouro verde"), que têm de ser protegida de uma extração não remunerada ("biopirataria”) por pesquisadores estrangeiros (DUTFIELD, 2004).

As discussões aceleraram durante as pré-negociações da Convenção sobre Biodiversidade, quando os governos dos países em grupos ambientais não governamentais formaram uma aliança a fim de evitar o que eles percebiam como uma exploração do Sul Global.

Considerando que os representantes governamentais priorizaram o valor econômico dos recursos biológicos de seus países, grupos ambientalistas focalizaram a preservação da natureza como um fim em si mesmo. Desde que eles geralmente aprovaram uma utilização econômica dos recursos biológicos, atores empresariais e países industrializados se abstiveram de uma rejeição total de suas reivindicações em vez de conseguirem evitar regras mais rigorosas e padrões aplicáveis para as atividades de bioprospecção (BASTOS, 2009; RAUSTIALA; VICTOR, 2004).

A convenção estipula que os recursos biológicos e recursos de conhecimento tradicional devem ser considerados propriedade pertencente à nação-estado de sua origem (GÖTTING, 2004). Comunidades locais indígenas são conceitualizadas como "detentores de conhecimento". Embora a convenção vagamente mencione o seu "consentimento prévio informado", centra-se na exploração de recursos genéticos e conhecimentos tradicionais associados.

A Convenção da Diversidade Biológica - CDB, estipula que qualquer bioprospecção será submetida a acesso equitativo e partilha de benefícios (ABS) entre todas as partes interessadas. A preponderância de uma utilização econômica de conhecimento das comunidades é inspirada na ideia de que a compensação monetária deve servir como um incentivo para preservar os recursos naturais e compartilhar conhecimento indígena com atores externos. No entanto, a CDB não tem qualquer indicação de como resolver as complexas questões técnicas que se seguem dessas disposições. 
O recém-acordado Protocolo de Nagoya, uma emenda da CDB, reforça um pouco o procedimento dos direitos das comunidades tradicionais e indígenas, mas geralmente permanece vago como a própria CDB.

Advogados indígenas argumentam que a lei ambiental internacional deve ser lida à luz de outras resoluções e declarações das Nações Unidas. Referem-se frequentemente à Convenção da Organização Internacional do Trabalho (OIT).

Embora a convenção não aborde diretamente o regulamento do conhecimento tradicional, ele claramente apoia as reivindicações indígenas de autodeterminação e o respeito pelo direito consuetudinário das comunidades tradicionais.

Nos últimos anos, grupos indígenas de defesa ganharam mais uma vitória em nível internacional. Eles insistiram com sucesso que a Declaração da ONU dos Direitos Indígenas (Nações Unidas, 2007) endossa o conceito de "livre consentimento prévio e informado", que também inclui o direito das comunidades indígenas a decidirem sozinhos e por suas próprias regras se querem ou não divulgar seus conhecimentos.

No entanto, o reconhecimento internacional dos direitos de comunidades tradicionais permanece bastante fraco, por várias razões. Além do fato de que muitos países industrializados não ratificaram a CDB (por exemplo, os Estados Unidos) ou a Convenção da OIT (o caso da Alemanha e da Índia, por exemplo), tratados internacionais sobre direitos ambientais e indígenas carecem de palavras globais e significados locais e mecanismos de fiscalização que garantam a conformidade dos seus estados signatários.

Além disso, os representantes indígenas frequentemente alegam que os secretários da CDB apoiam o instituto do acesso e repartição de benefícios, mas ainda não percebe o consentimento prévio como uma cláusula substantiva que deve ser reconhecida como um objetivo em si. Sempre que eles pedem uma concretização do consentimento prévio, o secretariado da $\mathrm{CDB}$, representantes do Estado e grupos ambientais transnacionais permanecem não comprometidos (CDB, 2011).

O mesmo vale para outras organizações internacionais e mecanismos que lidam com questões ambientais e proteção do clima, por exemplo, a Convenção-Quadro das Nações Unidas sobre a Mudança do Clima, também conhecida ou o Mecanismo de Parceria para o Carbono Florestal do Banco Mundial (THOMPSON et al., 2011; EASTWOOD, 2011).

Pior ainda, os direitos das comunidades tradicionais estão seriamente comprometidos com tratados de comércio internacional que operam sob o guarda-chuva 
da Organização do Comércio (OMC) e a Organização Mundial da Propriedade Intelectual (OMPI).

De extrema importância é o Acordo sobre o Comércio dos Direitos de Propriedade Intelectual - TRIPS (WTO, 1994). Devido aos intensivos esforços de lobby dos representantes da indústria dos EUA e da Europa e de segmentos do governo dos EUA, quase todos os países em desenvolvimento e emergentes assinaram o acordo da OMC (maio 2006).

Embora sua formulação não aborde explicitamente o conhecimento tradicional, o TRIPS estipula que "as patentes serão concedidas em todos os campos da tecnologia" (TRIPS, Art. 27).

Isso não significa que o CT seja diretamente patenteável, visto que não atende aos requisitos necessários. Muito pelo contrário, o conhecimento tradicional per se é excluído da elegibilidade da patente, porque não é considerado "novo" no sentido de uma responsabilidade de uma invenção individual (DUTFIELD, 2011).

No entanto, o acordo TRIPS estipula uma dicotomia entre inovações patenteadas, que não devem ser imitadas sem o consentimento do detentor da patente, e tecnológico não patenteável conhecimento, que é percebido como um bem público e livre para ser usado por todos.

Isso significa que os pesquisadores podem obter proteção de patente para invenções derivadas da utilização do CT. Assim, os tratados favorecem claramente as indústrias de ciências da vida (principalmente em países em desenvolvimento) em detrimento dos países fornecedores (ROSENDAL, 2006).

Por quase 15 anos, tanto grupos indígenas quanto governos de países em desenvolvimento exigiram que o ADPIC (Acordo TRIPS) fosse emendado para endossar o reconhecimento do CT relacionado à biodiversidade. Em 2004, o Brasil forjou a coalizão dos "Amigos do Desenvolvimento", a fim de avançar uma emenda ao TRIPS que introduziria um "requisito de divulgação", a Índia aproveitou o movimento para colaborar com a pressão na relativização da legislação internacional.

A emenda solicitaria aos solicitantes de patente que declarassem se suas invenções se baseiam em recursos de conhecimento biológicos e associados. No caso da bioprospecção, teriam de provar que respeitavam todos os regulamentos relevantes nos países de origem. Além disso, os países em desenvolvimento exigem que a falta de informações precisas ou uso enganoso em pedidos de patente levaria à revogação de uma patente. 
Enquanto grupos ambientais permanecem à margem, representantes governamentais dos países industrializados rejeitam fortemente essa afirmação. Os mais vociferantes adversários são dos EUA, Alemanha, Grã-Bretanha e França, cujos governos são intensamente pressionados por suas indústrias científicas.

Nessas circunstâncias, parece muito pouco provável que uma resolução recente do Parlamento Europeu (2012) para vincular o TRIPS com a CDB acabará sendo apoiada pela Comissão da EU ou pelos Estados membros no conselho.

Tudo somado, parece justo dizer que na estrutura internacional da tradição a regulamentação do conhecimento permanece ambígua, na melhor das hipóteses. Dentro do contexto de tratados ambientais, o CT é percebido predominantemente como meio de preservar os recursos naturais por meio de sua potencial valorização. Essa perspectiva difere significativamente das convenções da OIT e da ONU, que estipulam a aceitação dos direitos consuetudinários das comunidades indígenas.

No entanto, tanto o foco na proteção ambiental dos direitos tradicionais e das comunidades tradicionais contrasta com os do direito comercial, que endossa de um modo geral os interesses econômicos dos países industrializados e suas corporações. Devido às ambivalências de complexidade do regime internacional, o equilíbrio específico entre os diversos interesses no domínio das políticas tradicionais do conhecimento parece depender da implementação doméstica.

No decorrer dos capítulos apontou-se, por meio de exemplos como apoio, que o sistema jurídico atual não é eficaz na proteção das comunidades tradicionais, das terras tradicionais e, consequentemente, dos Conhecimentos Tradicionais. Nesta pesquisa, realizou-se viagem de sensibilização à Índia e pôde-se testemunhar diversos casos de sucesso e não sucesso de proteção do CT. Verificou-se, ainda, diversas formas de conhecimentos tradicionais, algumas dominantes, outras periféricas. As primeiras melhor protegidas pelo direito, embora ainda vulneráveis em relação às expropriações e processos de patentes internacionais. Os segundos, mais vulneráveis menos inseridos nos sistemas de proteção local ou internacional. Igualmente, houve a oportunidade de visitar diversas terras indígenas no Brasil.

Nelas perceberam-se realidades práticas que impedem os detentores de CTs de usar o Direito de Propriedade Intelectual convencionais para proteger seus conhecimentos tradicionais. Isso inclui, por exemplo, dificuldade em formular solicitações que atendam aos requisitos rigorosos de aplicação de DPI, recursos 
financeiros limitados para cobrir altas taxas de inscrição e eventuais custos de execução, falta de informações e afins.

Existe um consenso geral de que novas abordagens e medidas (sistemas sui generis) que combinam ferramentas de maneira apropriada precisam ser desenvolvidas para a proteção do CT nos níveis nacional e internacional.

Todavia, por falta de técnica na área da antropologia, não se pôde fazer investigação de campo apropriada. Dessa forma, escolheu-se utilizar os exemplos para colaborar com os argumentos jurídicos do texto. Outrossim, os exemplos narrados foram instruídos com documentos acadêmicos que corroboram com o fato narrado.

Nesse sentido, a colonização europeia apresenta uma importante fonte potencial de variação exógena na distribuição de instituições ao redor do mundo. North (1990) e La Porta et al (1998a; 1998b) acreditam que os caminhos de desenvolvimento das economias coloniais são explicados pelas identidades das nações europeias colonizadoras. North (1990) e North e Weingast (1989) argumentam que enquanto a Inglaterra, com o triunfo do Parlamento, emergiu com direitos de propriedade seguros e um sistema judicial imparcial, a burocracia centralizada da Espanha e de Portugal levou a pobres direitos de propriedade e sistemas legais. La Porta et al. (1988a, 1988b) descobriram que as nações que adotaram a lei comum britânica, em vez da lei civil, que se origina do direito romano, possuíam regras legais mais fortes que protegem os acionistas e credores corporativos.

Engerman (1997) e Sokoloff (2000) e Acemoglu et al. (2001) acreditam que a distribuição de instituições em todo o mundo também foi significativamente influenciada pelas condições geográficas locais. Para Engerman e Sokoloff, instituições com autonomia limitada surgiram nas colônias do Novo Mundo no Caribe, no Brasil e no sul dos Estados Unidos, onde a geografia e o clima são adequados para economias de monoculturas.

Para Acemoglu et al. (2001), a distribuição das instituições é determinada pelas condições iniciais de mortalidade dos assentamentos e densidade populacional nativa. Em lugares onde as taxas de mortalidade eram altas, os europeus não tinham o incentivo para se estabelecer em grande número e estabelecer a forma mais democrática de instituições desenvolvidas na Europa. Da mesma forma, em lugares onde os europeus encontraram densas populações nativas, como nos impérios mongol, asteca e inca, Acemoglu et al. argumentam que os europeus simplesmente assumiram as instituições nativas existentes que favoreciam as elites locais. 
Entretanto, o caso da Índia não se enquadra perfeitamente em nenhuma das nossas atuais categorias de entendimento sobre o tema das instituições e desenvolvimento coloniais. Assim como o Brasil, a Índia é dotada de clima tropical, solo fértil e possuía uma grande população nativa. Contudo, apesar do pequeno número de imigrantes britânicos, o governo britânico estabeleceu instituições na Índia com base em direitos de propriedade privada e um sistema judicial de tipo inglês para as populações nativas.

Existem várias causas potenciais de divergência nas economias entre distritos latifundiários e não proprietários durante os períodos pré e pós-independência. Os impostos poderiam ser ajustados ao contrário das áreas de senhorio, onde as taxas de impostos eram fixadas permanentemente. ${ }^{7}$ Segundo, as áreas de senhorios enfrentavam maiores problemas de agência na agricultura. Nas áreas de proprietários, a maioria das fazendas era trabalhada por meeiros, ao passo que nas áreas de não proprietários, era cultivada por proprietários e locatários. ${ }^{8}$ Terceiro, nos distritos de latifundiários, as reformas de inquilinos aumentaram o nível de incerteza dos direitos de propriedade. ${ }^{9}$ Finalmente, os gastos do distrito local em bens públicos, como educação ou estradas, podem diferir entre áreas de proprietários e não proprietários. Os níveis variáveis de gastos podem refletir diferenças nas preferências das elites locais ou diferenças na capacidade dos governos locais de resolver problemas de ação coletiva.

Estima-se o impacto dos sistemas de receita da terra no desempenho econômico, adotando-se a abordagem empírica usada em Banerjee e Iyer (2005). Medidas de desempenho econômico tiveram regressão em variáveis de controle geográfico, duração do domínio britânico, e se um distrito foi historicamente organizado como um senhorio ou um distrito não senhorio. Enquanto Banerjee e Iyer enfocam a produtividade agrícola e os investimentos, ampliou-se a investigação para outras medidas de desenvolvimento, como a urbanização, o emprego na indústria e nos serviços e a densidade populacional nos períodos pré e pós-independência. Todo este processo vem expropriando as terras das comunidades tradicionais Adivasis, que foram sendo retiradas de seus territórios nativos para a plantação de chá na administração Britânica.

Pouco se sabe sobre a relação entre as comunidades adivasis e não-adivasis durante as regras hindu e muçulmana. Existem referências perdidas a guerras e alianças entre os reis Rajput e chefes tribais na Índia central e no Nordeste entre os reinos Ahom do vale de Brahmaputra e a colina Nagas. Eles são considerados ati-sudra com significado menor que as castas intocáveis. Ainda hoje, o povo da casta superior se 
refere a esses povos como jangli, um termo pejorativo que significa "aqueles que são como animais selvagens" - não civilizados ou sub-humanos. Os grupos subjugados tornaram-se castas forçadas a realizar trabalhos menos desejáveis, como limpeza, limpeza de excrementos, remoção de cadáveres, trabalhos com couro etc. - "os intocáveis". Algumas das primeiras sociedades de pequena escala dependentes de caça e coleta e a agricultura tradicional parecem ter permanecido fora desse processo de aglomeração. Esses são os adivasis dos dias atuais. Sua existência autônoma fora do mainstream levou à preservação de suas práticas sócio-religiosas e culturais, a maioria delas mantendo também suas línguas distintas. A queima de viúvas, a escravização, a diferenciação ocupacional, a ordenação social hierárquica, entre outros, geralmente não estão presentes. Embora houvesse comércio entre os adivasis e a sociedade dominante, qualquer forma de relação social era desencorajada. A casta índia não tentou conscientemente atraí-los para a órbita da sociedade de castas.

Todavia, apesar do discurso dominante contra sua cultura, suas terras são historicamente utilizadas para cultivo agrícolas.

Durante os últimos 30 anos, o conhecimento tradicional destas comunidades despertou a atenção de cientistas, corporações e grupos ambientais. Ambos, cientistas de instituições públicas de pesquisa e atores corporativos das ciências da vida e indústria agrícola, percebem o CT como meios com os quais acelerar sua pesquisa em novas drogas e métodos de agricultura (DUTFIELD, 2011; PANDIKUMAR et al., 2011).

Mais recentemente, organizações ambientais não governamentais começaram a fazer uso do conhecimento dos indígenas para esquemas de proteção climática como o Clean Develop, mecanismo de Desenvolvimento (MDL) ou Redução de Emissões do Desmatamento e Programas de Degradação (REDD) (DEBBARMA, 2006).

Não obstante, a maioria dos atores externos só percebe conhecimento como matéria-prima útil para seus próprios fins, tendendo a ignorar suas ramificações socioculturais e desconsiderando os direitos consuetudinários das comunidades afetadas (AGRAWAL, 2002).

Dentro de múltiplos fóruns internacionais, negociadores de países emergentes e países industrializados, representantes da indústria, cientistas, sociedade civil, atores e grupos indígenas tentam chegar a um entendimento comum sobre padrões mutuamente aceitáveis para bioexplorações e atividades relacionadas.

Embora não haja um tratado internacional único que trate exclusivamente do conhecimento tradicional, muitos acordos, convenções e resoluções tocam nesse 
assunto. No entanto, a complexidade do regime internacional (Raustiala e Victor 2004) contém muitos aspectos ambivalentes, inconsistentes e prescrições contraditórias absolutas, o que deixa algum espaço para a interpretação durante o curso de implementação doméstica.

Este trabalho tem o objetivo de abordar o impacto da complexidade do regime internacional sobre iniciativas reguladoras nacionais em relação ao CT. No nível interno, concentra-se em abordagens regulatórias divergentes na Índia e Brasil.

O modelo ecocapitalista indiano prioriza o desenvolvimento econômico, investigação científica e, embora em menor grau, a proteção do ambiente. As regulamentações brasileiras nesse campo, em contraste, são inspiradas pelo tema do socioambientalismo, por meio do qual a exploração econômica e científica do conhecimento tradicional é equilibrada com o respeito pelos indígenas e os direitos consuetudinários das comunidades locais. A estrutura internacional apoia as regulamentações indianas, enquanto a abordagem é desestabilizada pela legislação de propriedade comercial e intelectual internacional. 


\section{CONCLUSÃO}

Conforme apresentado neste trabalho, as políticas tradicionais de conhecimento são moldadas por uma complexa interação entre o direito internacional, os regulamentos e práticas locais.

Embora o quadro internacional não determine uma abordagem única para conciliar os interesses divergentes neste campo, oferece uma base ideológica que estabelece o rumo para as iniciativas, por meio do seu impacto sobre a eficácia das diferentes abordagens.

Perspectivas alternativas, como sugeridas pela Convenção da OIT e da Declaração da ONU sobre Direitos Indígenas, não são completamente descartadas, mas permanecem bastante marginalizadas.

As comunidades indígenas reconhecem agora que a biodiversidade pode ser um recurso natural valioso, em seus territórios, uma fonte valiosa de nutrição, e que suas práticas agrícolas tradicionais são vitais para manter sua coesão social. Os estudos de caso da Índia e do Brasil ilustram que o quadro internacional ainda deixa espaço para alguma flexibilidade no que diz respeito às prioridades internas, mas favorece a lógica da mercantilização.

A abordagem indiana, que consiste em documentar o conhecimento tradicional para fins econômicos e fins ambientais, é facilitada pela CDB e pela lei internacional de patentes.

A abordagem brasileira, com seu foco na autodeterminação indígena, sofre da falta de um mecanismo de aplicação internacional, que também desestabiliza sua aplicação no nível doméstico.

Em suma, o quadro internacional ideologicamente favorece a perspectiva de que o conhecimento tradicional é um potencial bem comercial, a utilização deste deve servir para o desenvolvimento econômico e objetivos ambientais.

Abordagens alternativas que enfocam os direitos dos costumes indígenas e autodeterminação das comunidades tradicionais não são ignoradas, mas a sua aplicação prática é seriamente impedida.

Essa discussão apresentou uma possível abordagem inicial que poderia ser adotada em nível nacional por países interessados em abordar questões de CT. Um primeiro passo sugerido é avaliar a situação atual relacionada ao Conhecimento Tradicional no país, incluindo, por exemplo, determinar os principais tipos de CTs, 
quem são os portadores de Conhecimentos Tradicionais, como o CT está sendo usado, quais são as políticas atuais e institucionais e quem são os principais interessados e partes interessadas. O próximo passo poderia ser o diálogo político nacional com participação múltipla (com participação total dos detentores de Conhecimentos Tradicionais), a fim de compartilhar as conclusões da avaliação e discutir os objetivos que um sistema nacional sui generis deve abordar. Para cada uma das três grandes categorias de objetivos relacionados ao CT - preservação, proteção e promoção (aproveitando o TK para o desenvolvimento) - a discussão delineou uma série de possíveis ferramentas e medidas políticas. Esse menu não exaustivo de opções destinase a servir como ponto de partida para uma maior exploração e discussão. Uma abordagem holística para o problema é essencial.

A discussão também examinou algumas das preocupações expressas em nível internacional em relação aos conhecimentos tradicionais. Muitos pedidos têm sido feitos por países em desenvolvimento e outros países para a proteção internacional dos CTs, visto que as políticas nacionais têm efeito limitado além das fronteiras nacionais. Duas propostas que merecem ser examinadas são a proposta "defensiva" para exigir que os pedidos de patentes incluam a divulgação da origem dos recursos genéticos e Conhecimentos Tradicionais, bem como evidências de conhecimento prévio e repartição de benefícios; e a proposta "positiva" de um quadro internacional que reconheça os sistemas sui generis nacionais e/ou regionais.

Mais trabalho é necessário em ambos os níveis: elaboração de elementos dos sistemas nacionais, bem como soluções internacionais. Do ponto de vista do desenvolvimento, a solução definitiva para o desafio multidimensional dos CTs será uma combinação de medidas multifacetadas em nível nacional e internacional.

Mais pesquisas devem abordar simultaneamente a comunidade em nível doméstico, a fim de compreender a dinâmica das tradicionais políticas de conhecimento.

A interpretação correta do Artigo 8 (j) é objeto de extenso e contínuo debate internacional. A CDB previu a utilização de regimes nacionais e internacionais de propriedade intelectual para promover e proteger o conhecimento tradicional.

O Artigo 16 aborda o acesso e transferência de tecnologia e afirma que, se o conhecimento estiver sujeito a direitos de propriedade intelectual, "o acesso e a transferência serão fornecidos em termos que reconheçam e coerente com a proteção adequada e efetiva dos direitos de propriedade intelectual". 
Os vínculos da $\mathrm{CDB}$ do conhecimento tradicional aos sistemas existentes de propriedade intelectual também definem os dois em um possível curso de colisão, exigindo proteção adequada e efetiva dos direitos de propriedade intelectual e que os direitos de propriedade intelectual são os objetivos da CDB.

Conhecimento e práticas tradicionais são vistos como mais do que uma fonte de invenções patenteáveis que geram receita. A CDB lista as práticas culturais tradicionais como um método para o uso sustentável de diversidade.

Na medida em que as práticas culturais tradicionais são compatíveis com os requisitos de conservação ou uso sustentável, esses usos devem ser protegidos e incentivados.

A importância de resolver as questões do Artigo 8 (j) é ressaltada pela existência de um grupo de trabalho específico das Partes Contratantes, bem como a inclusão do Artigo 8 (j) e "Questões para uma consideração profunda".

A falta de linguagem específica na CDB significa que os princípios de conservação são definidos apenas em termos vagos. Por exemplo, as partes são encorajadas a desenvolver estratégias para a partilha de benefícios "justa e equitativa", mas nem "justas" nem "equitativas" é definido na CDB.

O mesmo problema é encontrado com o "consentimento prévio informado" requerido para acesso a recursos do Artigo 15. O Artigo 3 reconhece que os Estados têm o "direito soberano de explorar suas próprias políticas ambientais", e o Artigo 6 exige que as partes contratantes* desenvolvam estratégias nacionais... as quais devem refletir, entre outras, as medidas estabelecidas na presente Convenção que sejam relevantes para a Parte Contratante interessada.

Constituir consentimento não é especificado, e a autoridade dada nos artigos $3 \mathrm{e}$ 6 significa que o Estado define os termos de consentimento, se as partes envolvidas no intercâmbio de conhecimentos e recursos biológicos deram realmente o seu consentimento.

A imprecisão da linguagem na Convenção pode ter sido intencional, na medida em que a terminologia imprecisa dos governos à máxima flexibilidade na implementação dos termos da CDB como entenderem.

A falta de orientação no texto da CDB não foi admitida desde as reuniões da Conferência das Partes, pois após a entrada em vigor da Convenção abordaram temas da CDB e esclareceram algumas áreas de confusão. 
No entanto, muitos países aprovaram legislação para implementar a CDB na legislação nacional antes de se beneficiarem das reuniões em andamento que esclarecem a terminologia.

Portanto, a legislação nacional tende a usar os mesmos termos vagos usados no texto da Convenção, e isso cria incerteza quando funcionários do governo tentam traduzir a legislação nacional em ação.

A CDB exige que as partes contratantes implementem a convenção na lei nacional, mas no Brasil, os governos estaduais foram os primeiros a agir de acordo com os princípios da CDB. A distinção de ser o primeiro a regulamentar o acesso a recursos genéticos no Brasil pertence ao estado do Acre, no oeste da Amazônia e pouco povoado, que promulgou sua lei de biodiversidade em julho de 1997.

A lei do Acre codifica muitos dos princípios da CDB e criou o modelo para a legislação federal aprovada cinco anos mais tarde. A contribuição mais importante da lei do Acre é que, na época, identificou a ausência de um método nacional para proteger o conhecimento tradicional das comunidades indígenas e locais.

A lei estadual reconheceu o valor do conhecimento associado a recursos genéticos e fez provisões especiais para conhecimento tradicional e propriedade intelectual.

O Artigo 41 diz que as comunidades locais se beneficiarão coletivamente de seus conhecimentos tradicionais, incluindo os direitos de propriedade intelectual. A lei reconhece que alguma propriedade intelectual relacionada à biodiversidade pode ser atribuída a uma propriedade intelectual individual e exige que os conhecimentos relativos à biodiversidade que não podem ser atribuídos a um indivíduo sejam tratados como propriedade intelectual coletiva.

A lei também diz que os direitos coletivos de propriedade intelectual são aqueles que incluem direitos ancestrais e conhecimento adquirido. Isso levanta uma questão importante sobre se toda a comunidade pode ser considerada conhecimento possuído por alguns.

Se conhecimento comunal segmentado ou restrito parecer paradoxal, considere uma instância em que apenas membros selecionados de uma comunidade têm acesso a uma determinada prática, como o conhecimento possuído por um curandeiro tradicional.

O curador pode ser a única pessoa que tem acesso e sabe como usar certas práticas passadas por meio das gerações. O curador é o detentor do conhecimento, mas a comunidade é dona do conhecimento. 
Em outras palavras, o conhecimento tradicional é de propriedade e transmitido coletivamente, mas ainda pode ser segmentado ou reivindicado com base na classificação social.

A omissão gritante da lei do Acre é a definição do conhecimento tradicional. A lei define "local e comunidade indígena". e "provedor de conhecimento tradicional", mas nunca define o conhecimento tradicional em si. Outro estado da Amazônia, o Amapá aprovou sua própria lei de biodiversidade em dezembro do mesmo ano. A regulação da propriedade intelectual e de terras indígenas é de domínio do governo federal.

Portanto, a aprovação das leis de biodiversidade no Acre e no Amapá devem ser vistos como declarações ousadas sobre a importância do conhecimento tradicional ou de exercícios fúteis. Em qualquer caso, estas duas leis estaduais e representantes federais dos estados da Amazônia estimularam o governo federal a agir.

Um dos principais apoiadores no Congresso da legislação federal que regula o acesso a recursos genéticos foi a então Senadora do Acre. Ainda percebe-se um desafio em função da nova dimensão acerca do conceito de soberania e da necessidade de se proteger a pessoa humana e, em especial, as populações indígenas. A criação de mecanismos específicos no âmbito da ONU representa a consolidação da categoria dos direitos humanos como parâmetro universal, os quais passaram a ser positivados em documentos internacionais, como a Declaração de Direitos dos Povos Indígenas e Tribais e a Convenção número 169 da OIT. Em verdade, o que se verifica é uma pretensão de validade universal.

Assim, as temáticas relativas aos direitos internacionais dos povos indígenas passam a ser assunto que supera o âmbito interno de cada Estado, assumindo-se como pressuposto à universalidade desses direitos. Isso produz um efeito de afirmação internacional de direitos. Todavia, generaliza necessidades específicas, o direito à diferença dos povos indígenas que, contudo, em que pese a confirmação da relevância da temática dos direitos dos povos indígenas no âmbito internacional, os institutos de proteção dos povos indígenas enfrentam o desafio de torná-los efetivos a despeito de sua positivação. Apesar do processo de positivação, esses direitos continuam sendo violados no âmbito local dos Estados. Verifica-se, então, que a simples adesão formal pelos Estados, aos documentos internacionais que afirmam direitos, não garante sua aplicação, ou sequer a sua aplicabilidade no âmbito interno dos Estados. Nesses termos, uma contradição entre a proclamação teórico-normativa dos direitos e sua inobservância 
prática é revelada. Aqui foi exposto o problema da não ratificação da convenção da OIT pela Índia. Por esse motivo, o problema do direito internacional pode não ser filosófico, mas apenas jurídico e político ${ }^{308}$.

As críticas referem-se, sobretudo, à estrutura do discurso do direito internacional dos povos indígenas, tratando-se de uma estratégia de emancipação que compreende a emancipação destes como titulares de direitos específicos e preestabelecidos.

Assim, essa definição dos povos indígenas como sujeitos internacionais de direitos centra muito a resolução de questões (i) no próprio Direito; e (ii) no Estado, como único responsável pela garantia de efetividade desses direitos. Por um lado, o formalismo e a linguagem asséptica, do Direito, afastam as comunidades tradicionais, da condição de autonomia sobre sua própria situação. Por outro lado, proporciona uma "superlegitimação" do Estado, em abstrato, como responsável pela alocação dos direitos, ignorando a sua permeabilidade ao poder político e econômico.

Nesse contexto, o tratamento dado às comunidades tradicionais de forma genérica tornou-se insuficiente no atendimento às particularidades e peculiaridades das violações dos direitos. Na maioria das comunidades periféricas, fez-se, assim, premente a especificação de sujeitos de direito, evidenciando a necessidade de conferir a determinados grupos e indivíduos o tratamento e a proteção especial particularizados mediante suas vulnerabilidades. Isto é, as diferenças não podem ser ignoradas pela igualdade de direitos, mas sim detalhadas no sentido da promoção de direitos. Remetendo, assim, a máxima sobre igualdade de direitos formulados pelo filósofo da Grécia Antiga, Aristóteles, que traduz a justiça, em termos cognitivos, como o tratamento igual para os iguais e desiguais para os desiguais. No mesmo sentido, Immanuel Kant, que afirma a construção da ética universal a partir dos imperativos categóricos, em sua obra, A Crítica da Razão Pura.

Nesse sentido, a autonomia da vontade e o princípio universal situam o homem no centro do universo do direito. Tendo em vista os dilemas que permeiam a realidade histórica do processo de positivação dos direitos indígenas, há que se atentar para a necessidade de se traduzir a linguagem de aproximações entre as diferenças e conflito sociais. Nesse sentido, destaca-se que a universalidade atribuída ao direito internacional pode ter o efeito de invisibilizar as diferenças que constituem as diversas possibilidades

\footnotetext{
${ }^{308}$ Norberto Bobbio afirma, portanto, que o problema de fundamentação filosófica dos direitos humanos está resolvido, na medida em que existe significativa composição normativa desses direitos, sendo suficiente colocá-los em prática, tal como se encontram positivados.
} 
de manifestação concreta das comunidades tradicionais, em especial, aqueles referentes às identidades particulares de cada cultura. Assim, o discurso universalista reconhece a existência de elementos valorativos comuns compartilhados por todos os homens, individuais ou coletivamente, mas ignora muitas vezes a possibilidade de as distintas culturas poderem configurar a diferença como um valor, ainda que se entenda a diversidade, em tese, como acontecimento e características intrínsecos à condição humana. No caso das populações autóctones e a legislação internacional de proteção aos povos indígenas, o supracitado direito à terra, previsto na convenção 169 da OIT e Declaração dos Direitos dos Povos Indígenas, aplicado sem se levar em consideração as particularidades da relação dessas comunidades com o espaço que ocupam pode levar o direito a ser aplicado à norma em abstrato a cometer equívocos no momento de interpretar a lei, por exemplo. Por esse motivo o normativismo jurídico, ao ignorar, reduzir ou generalizar os valores, esvazia o argumento da eficácia da norma, torna a norma insuficiente para responder às demandas sociais das populações indígenas. A efetividade do direito internacional das comunidades indígenas está vinculada à condição de sua aplicabilidade, ou realização fática. Nesse sentido, encontram-se na doutrina múltiplas formas de interpretação imbuídas na vontade de melhor compreender seu conceito. $O$ instituto da eficácia analisa a real aplicação das normas no plano dos fatos, pelos seus destinatários. Em suma, a efetividade da norma jurídica se traduz na “obediência ou cumprimento desta norma pelos integrantes da sociedade".

A anuência do indivíduo às suas predeterminações é o fato que reconhece a norma. Ou seja, o indivíduo incorpora a norma ao agir em consonância com suas determinações, isso pode ocorrer por mera conveniência, por costume ou por medo de sanções relacionadas ao não cumprimento da norma. Por outro lado, Tércio Sampaio relaciona a efetividade da norma jurídica com o sucesso em sua obediência.

Nesse sentido, verifica-se que a aplicação da norma se relaciona com a questão de sua eficácia. Nos termos da complexidade do tema, é importante ressaltar que as normas jurídicas nem sempre geram efeitos imediatos. Temos que a noção de eficácia para Norberto Bobbio implica a necessidade de materializar o cumprimento das normas pelos seus destinatários. A eficácia jurídica e a eficácia social, então, materializam a efetividade da norma jurídica, na medida em que garantem a realização de seu preceito na sociedade. A defesa restrita da dimensão positiva dos direitos humanos leva, igualmente, a simples imposições pautadas pelo argumento de autoridade legal, que podem acarretar efeitos insuficientes ou, em casos extremos, contrários aos pretendidos, 
como o surgimento de conflitos de base cultural. A perspectiva dos direitos humanos que se pauta somente por mecanismos normativos é insuficiente, mas isso não significa que a sua positivação seja desnecessária. O problema central do positivismo jurídico é o afastamento do campo do Direito de reflexões sobre a justiça, de maneira que considera como "norma jurídica e [...] nada mais do que norma". A febril positivação dos direitos humanos, por si só, não resolve a ampla problematização que os envolve. Nesses termos, sobretudo em face do pluralismo cultural das comunidades tradicionais, a fundamentação filosófica dos direitos é importante, porque transcende criticamente o campo estrito do positivismo jurídico, ao se inserir no domínio da ética, ao perquirir sobre a "razão justificativa", a "fonte legitimadora", a ratio essendi dos direitos humanos.

A ideia da relevância dos direitos humanos enquanto categoria ético-jurídica encontra aprovação generalizada no contexto global contemporâneo, sobretudo do ponto de vista retórico-discursivo e teórico. A valorização dos direitos humanos é corroborada pela ampla composição normativa existente, tanto no plano internacional, quanto nos planos nacionais como expressões de direitos fundamentais. Todavia, o fenômeno da ampla positivação desses direitos não deve ensejar a errônea ilação de que existe efetividade e o seu pleno reconhecimento, sobretudo, em face do fato do pluralismo cultural.

Nesse sentido, a compreensão da relação que se constitui entre as ideias-chave "Direitos Humanos" e "Cultura" surge, nesse contexto, como uma questão de fundamental importância, tanto do ponto de vista da fundamentação dos direitos humanos, quanto do ponto de vista da sua efetividade. Considerando o contexto fático de pluralismo cultural e na medida em que fundamentação e efetividade são questões que se atrelam, a importância da fundamentação intercultural é sentida enquanto parâmetro legítimo para firmar a mediação entre universalidade e diversidade cultural. A perspectiva de fundamentação intercultural dos direitos humanos, assim, afasta reducionismos, não limita a complexidade epistemológica à simples análise exegética de textos legais nacionais e/ou internacionais, e visa identificar filosoficamente fins e valores comuns que informem a especial categoria dos direitos humanos.

Em face de todo o exposto, pode-se resumir de forma clara e objetiva, que o positivismo jurídico representou a introdução do positivismo filosófico para o mundo do Direito, na pretensão de criar-se uma ciência jurídica, com características análogas às ciências exatas e naturais. A busca positivista pela objetividade científica separou 
definitivamente o Direito da moral, concebendo o fenômeno jurídico como uma emanação do Estado com caráter imperativo e coativo, passando a fundar-se em juízos de fato e não em juízos de valor, representando, assim, uma tomada de posição diante da realidade, sujeitando-se a uma crítica severa. Consoante ao exposto, verificou-se que a teoria positivista, ou seja, a ideia de que a ampliação da positivação das normas jurídicas e de mecanismos de proteção de direitos equivale a um caminho necessário e suficiente para a proteção dos direitos, não atende às demandas idiossincráticas relativas aos direitos humanos. No âmbito do direito, o debate sobre a necessidade, importância e eficácia da expansão da positivação dos direitos para sua proteção e dada à demanda pela redução das assimetrias centro - periferia no globo.

Em tempos mais recentes, a temática dos direitos humanos assumiu o papel de destaque que poderá promover reflexões mais profundas acerca da necessidade de sua efetividade para diminuição das assimetrias globais. Enquanto medidas de proteção aos direitos humanos claramente partem da agenda internacional, a preocupação com o problema de sua efetividade ganhou espaço no mesmo processo de positivação. Embora a lei se manifeste de forma diferente em diferentes microcontextos, isso não diminui o fato de que a lei estatutária em si, muitas vezes, tem impactos muito devastadores, no sentido imediato, em todas as regiões onde uma determinada lei se aplica. Se o regime político se torna uma barreira para a aplicação da legislação programática, será necessária uma atuação que ultrapassa o âmbito do direito para a aplicação da legislação de modo que atenda às necessidades das maiorias bem como das minorias, dentro dos princípios democráticos.

Conforme apresentado neste trabalho, as políticas tradicionais de conhecimento são moldadas por uma complexa interação entre o direito internacional, os regulamentos e práticas locais.

Embora o quadro internacional não determine uma abordagem única para conciliar os interesses divergentes nesse campo, oferece uma base ideológica que estabelece o rumo para as iniciativas, por meio do seu impacto sobre a eficácia das diferentes abordagens.

O quadro internacional é predominantemente caracterizado por uma percepção capitalista do conhecimento. Isso também vale para comércio e direito do meio ambiente, bem como para as atividades das organizações internacionais (ZELLER, 2008). Perspectivas alternativas, como sugerido pela Convenção da OIT e da 
Declaração da ONU sobre Direitos Indígenas, não são completamente descartadas, mas permanecem bastante marginalizadas.

Os estudos de caso da Índia e do Brasil ilustram que o quadro internacional ainda deixa espaço para alguma flexibilidade no que diz respeito às prioridades internas, mas favorece a lógica da mercantilização.

A abordagem indiana, que consiste em documentar o conhecimento tradicional para fins econômicos e fins ambientais, é facilitada pela CDB e pela lei internacional de patentes.

A abordagem brasileira, com seu foco na autodeterminação indígena, sofre da falta de um mecanismo de aplicação internacional, que também desestabiliza sua aplicação no nível doméstico.

Em suma, o quadro internacional ideologicamente favorece a perspectiva de que o conhecimento tradicional é um potencial bem comercial, a utilização dos quais deve servir para o desenvolvimento econômico e objetivos ambientais.

Abordagens alternativas que enfocam os direitos dos costumes indígenas e autodeterminação das comunidades tradicionais não são ignorados, mas a sua aplicação prática é seriamente impedida.

Parece prematuro avaliar se a submissão a um capitalista é a única alternativa praticável (HARVEY, 1996). Mais pesquisas devem abordar simultaneamente a comunidade em nível doméstico, a fim de compreender a dinâmica das tradicionais políticas de conhecimento.

A interpretação correta do Artigo 8 (j) é objeto de extenso e contínuo debate internacional. A CDB previu a utilização de regimes nacionais e internacionais de propriedade intelectual para promover e proteger o conhecimento tradicional.

O Artigo 16 aborda o acesso e transferência de tecnologia e afirma que, se o conhecimento estiver sujeito a direitos de propriedade intelectual, "o acesso e a transferência serão fornecidos em termos que reconheçam e coerente com a proteção adequada e efetiva dos direitos de propriedade intelectual.

Os vínculos da $\mathrm{CDB}$ do conhecimento tradicional aos sistemas existentes de propriedade intelectual, mas também definem os dois em um possível curso de colisão, exigindo proteção adequada e efetiva dos direitos de propriedade intelectual e que os direitos de propriedade intelectual são os objetivos da CDB. 
Conhecimento e práticas tradicionais são vistos como mais do que uma fonte de invenções patenteáveis que geram receita. A CDB lista as práticas culturais tradicionais como um método para o uso sustentável de diversidade.

$\mathrm{Na}$ medida em que as práticas culturais tradicionais são compatíveis com os requisitos de conservação ou uso sustentável, esses usos devem ser protegidos e incentivados.

A importância de resolver as questões do Artigo 8 (j) é ressaltada pela existência de um grupo de trabalho específico das Partes Contratantes, bem como a inclusão do Artigo 8 (j) e "Questões para uma consideração profunda".

A falta de linguagem específica na CDB significa que os princípios de conservação são definidos apenas em termos vagos. Por exemplo, as partes são encorajadas a desenvolver estratégias para a partilha de benefícios "justa e equitativa", mas nem "justas" nem "equitativas" é definido na CDB.

O mesmo problema é encontrado com o "consentimento prévio informado" requerido para acesso a recursos do Artigo 15. O Artigo 3 reconhece que os Estados têm o "direito soberano de explorar suas próprias políticas ambientais", e o Artigo 6 exige que as partes contratantes* desenvolvam estratégias nacionais... as quais devem refletir, entre outras, as medidas estabelecidas na presente Convenção e que sejam relevantes para a Parte Contratante interessada.

Constitui consentimento não é especificado, e a autoridade dada nos artigos 3 e 6 significa que o Estado define os termos de consentimento, se as partes envolvidas no intercâmbio de conhecimentos e recursos biológicos deram realmente o seu consentimento.

A falta de orientação no texto da CDB não foi demitida desde as reuniões da Conferência das Partes, que após a entrada em vigor da Convenção abordaram temas da CDB e esclareceram algumas áreas de confusão.

No entanto, muitos países aprovaram legislação para implementar a CDB na legislação nacional antes de se beneficiarem das reuniões em andamento que esclarecem a terminologia.

Portanto, a legislação nacional tende a usar os mesmos termos vagos no texto da Convenção, e isso cria incerteza quando funcionários do governo tentam traduzir a legislação nacional em ação. Se conhecimento comunal segmentado ou restrito parecer paradoxal, considere uma instância em que apenas membros selecionados de uma 
comunidade têm acesso a uma determinada prática, como o conhecimento possuído por um curandeiro tradicional.

O curador pode ser a única pessoa que tem acesso e sabe como usar certas práticas passadas em gerações. O curador é o detentor do conhecimento, mas a comunidade é dona do conhecimento.

Os conhecimentos das comunidades tradicionais devem ser principalmente observados em relação, em primeiro lugar, ao reconhecimento dos direitos dos detentores do conhecimento tradicional original e, em segundo lugar, à aquisição não autorizada de direitos por terceiros sobre o conhecimento tradicional. Além disso, os mecanismos buscados para serem implementados em relação ao conhecimento tradicional devem fornecer uma apreciação do conhecimento original do conhecimento.

Existem duas formas de proteção à propriedade intelectual que lida com o conhecimento tradicional. E eles são, os detentores de conhecimento tradicional têm o direito de agir ou buscar remédios contra qualquer uso indevido do conhecimento tradicional. Qualquer sistema de proteção positiva do conhecimento tradicional deve prever: Reconhecimento de valor e promoção do respeito pelos sistemas tradicionais de conhecimento. Capacidade de resposta às necessidades atuais dos detentores de conhecimento tradicional. Suporte de sistemas tradicionais de conhecimento e capacitação de detentores de conhecimento tradicional. Promoção da partilha equitativa de benefícios do conhecimento tradicional. Promoção do uso do conhecimento tradicional para uma abordagem ascendente ao desenvolvimento. Salvaguarda contra direitos ilegítimos de propriedade intelectual adquiridos por terceiros sobre o conhecimento tradicional. Qualquer sistema de proteção defensiva do conhecimento tradicional deve prever: Um mecanismo para garantir que o conhecimento tradicional que constitui a técnica anterior esteja disponível e acessível às autoridades de busca 


\section{REFERÊNCIAS}

ACCIOLY, Hildebrando; NASCIMENTO e SILVA, Geraldo Eulalio; CASELLA, Paulo Borba. Manual de Direito Internacional Público. São Paulo: Saraiva, 2010.

AGRAWAL, Arun: Indigenous Knowledge and the Politics of Classification. In: International Social Science Journal, n. 54, v. 173, p. 287-297, 2002.

ALEXY, Robert. Constitucionalismo discursivo. Porto Alegre: Livraria do Advogado, 2007.

ALMEIDA, Marina Corrêa de. A cultura legal emergente latino-americana: o pluralismo jurídico rompendo os laços imperialistas no direito. Revista Brasileira de Estudos Latino Americanos, v. 1, n. 1, p. 38-50, jun., 2011.

ALTIERI, M. A. Agroecologia: bases científicas para uma agricultura sustentável. Guaíba: Agropecuária, 2002.

ANTUNHA, C.; BARBOSA, J. M. A.; FIGUEIREDO, P. O. Território do Conhecimento Tradicional: controvérsias em torno da aplicação da legislação de patentes aos conhecimentos indígenas. Revista Proa, ${ }^{\circ}$ 02, vol.01, 2010.

AQUINO, Tomás de. Escritos Políticos. $2^{\text {a }}$ ed. Petrópolis: Vozes, 2010.

ARISTÓTELES. Éthique à Nicomaque. Paris: Flammarion, 2004.

AZEVEDO, Cristina M. Regulation to Access to Genetic Resources and Associated Traditional Knowledge in Brazil. Biota Geotropica, v. 5, n. 1, p. 1-9, 2005.

BACHELARD, Gaston. A epistemologia. Lisboa: Edições 70, 2006.

BACHELARD, Gaston. A formação do espírito científico: contribuição para uma psicanálise do conhecimento. Rio de Janeiro: Contraponto, 1997.

BACON, Francis. Novum Organum. Madrid: Nueva Biblioteca Filosófica, 1933.

BAKHTIN, M. Marxismo e filosofia da linguagem. São Paulo: Hucitec, 1993.

BALDI, César Augusto. Direitos humanos na sociedade cosmopolita. Rio de Janeiro: Renovar, 2004.

BAPTISTA FILHO, Almir Cezar de Carvalho. Dinâmica, determinações e sistema mundial no desenvolvimento do capitalismo nos termos de Theotônio dos Santos: da Teoria da Dependência à Teoria dos Sistemas-mundo. 2009. 99f. Dissertação (mestrado em Economia) - Faculdade de Economia, Universidade Federal de Uberlândia, Uberlândia, 2009.

BARBOSA, D. B. Uma Introdução à Propriedade Intelectual. Rio de Janeiro: Lumen Júris, 2003.

BARBOSA, J. M. A.; BARBOSA, M. A. Direitos intelectuais e conhecimentos tradicionais: Estudo de caso Guarani-MBYA à face do Instituto do Patrimônio Histórico 
e Artístico Nacional - IPHAN. Revista da Faculdade de Direito UFG, v. 38, n. 1, p. 97-120, jul. /dez. 2014.

BARBOSA, Marco Antonio. Direito Antropológico e Terras Indígenas no Brasil. São Paulo: Plêiade, 2001.

BARBOSA, Marco Antonio. Os povos indígenas e as organizações internacionais: Instituto do Indigenato no direito brasileiro e autodeterminação dos povos indígenas. Revista Eletrônica História em Reflexão, vol. 1, n. 2, jul./dez. 2007.

BARRETTO, Vicente de Paulo. Direitos humanos e sociedades multiculturais. In:

BARZOTTO, Luis Fernando. Os Direitos Humanos como Direitos Subjetivos: da dogmática jurídica à ética. Revista da Procuradoria Geral do Estado, Porto Alegre, v. 28 , n. 59 , jun./2004, p. 137-175.

BASTOS, Rodolpho Zahluth: Rivalites Geopolitiques Sur La Biodiversite, L'enjeu De Regulation De L'acces Aux Ressources Genetiques Au Bresil. Universite de Paris VIII, Doctoral Thesis, 2009.

BEDOYA, E.; BEDOYA, A. Trabalho Forzoso na Extração da Madeira na Amazônia Peruana. OIT, Lima, 2005.

BELLINHO, Lilith Abrantes. Uma evolução histórica dos direitos humanos. Disponível em: <http://www.unibrasil.com.br/arquivos/direito/20092/lilith-abrantes-bellinho.pdf>. Acesso em: 10 out. 2018.

BENSUSAN, Nurit; LIMA, André. Quem cala consente? Subsídios para a proteção aos conhecimentos tradicionais. São Paulo: Instituto Socioambiental, São Paulo, 2003.

BENT, S.A [et al.]. Direitos de Propriedade Intelectual em Biotecnologia Worldwide. New York: Stockton Press, 1987.

BERNAL, John D. Historia social de la Ciência: la ciência em la historia. Vol. I. Barcelona: Edições Península, 1976.

BHABHA, Homi K. The Other Question. Screen, vol. 24, n.6, p.18-36, 1983.

BHARWADA Charul; MAHAJAN Vinay. Quiet Transfer of Commons. Economic and Political Weekly, v. 41, n. 4, , p. 314-15, 28 Jan. 2006.

BHATIA Bela; SUNDAR, Nandini; VIRGINIUS Xaxa. Scheduled Tribes Bill. Economic and Political Weekly, v. 40, n. 43, p. 4.566, out. 2005.

BHUSHAN, Prashant. Supreme Court and PIL. Changing Perspectives under Liberalisation, 2004.

BIELEFELDT, Heiner. Filosofia dos direitos humanos: fundamentos de um "ethos" de liberdade universal. São Leopoldo: Unisinos, 2003.

BIJOY, C. R. Adivasis Betrayed: Adivasi Land Rights in Kerala. Economic and Political Weekly, v. 34, n. 22, p. 1.329-35, 1999. 
BILDER, R. B. Direito e recursos naturais políticas internacionais. Natural Resources Journal, v. 20, p. 451-486, jul. 1980.

BITTAR, Eduardo C. B. Justiça e Emancipação: reflexões jusfilosófica a partir do pensamento de Jürgen Habermas. São Paulo: Quartier Latin, 2011.

BOBBIO, Norberto. A era dos direitos. Rio de Janeiro: Elsevier, 2004.

BOBBIO, Norberto. Teoria geral da política: a filosofia política e as lições dos clássicos. Rio de Janeiro: Elsevier, 2000.

BONAVIDES, Paulo. Curso de direito constitucional. 19ª ed. São Paulo: Malheiros, 2009.

BOURDIEU, Pierre. As regras da arte: gênese e estrutura do campo literário. São Paulo: Companhia das Letras, 1992.

BRASIL. Constituição da República Federativa do Brasil: texto constitucional promulgado em 5 de outubro de 1988, com as alterações adotadas pelas Emendas Constitucionais nos 1/1992 a 68/2011, pelo Decreto Legislativo $n^{\circ} 186 / 2008$ e pelas Emendas Constitucionais de Revisão nos 1 a 6/1994. - 35. ed. - Brasília, DF: Câmara dos Deputados, Edições Câmara, 2012.

BRASIL. Constituição da República Federativa. Disponível em: <http://www.planalto.gov.br/ccivil_03/constituicao/constituicao.htm Acesso em 201507-11>. Acesso em: 11 set. 2018.

BRASIL. Convenção da Biodiversidade Biológica. Disponível em: <http://www.mma.gov.br/estruturas/sbf_chm_rbbio/_arquivos/cdbport_72.pdf. Acesso em 2015-07-11>. Acesso em: 10 set. 2018.

BRASIL. Decreto n. 6.040, de 07 de fevereiro de 2007. Disponível em: <http://www.planalto.gov.br/ccivil_03/_ato2007-2010/2007/decreto/d6040.htm>.

Acesso em: 2 out. 2018.

BRASIL. Decreto no 8.072, sendo nominado a partir de 1918. Serviço de Proteção ao índio - SPI. Disponível em: <http://www2.camara.leg.br/legin/fed/decret/19101919/decreto-8072-20-junho-1910-504520-norma-pe.html>. Acesso em: 4 out. 2018.

BRASIL. Lei Federal $\mathbf{n}^{\mathbf{1 3}}$ 1323/2015. Disponível em: <http://www.planalto.gov.br/ccivil_03/_Ato2015-2018/2015/Lei/L13123.htm>. Acesso em: 24 out. 2018.

BRASIL. Medida Provisória 2186-16/2001. Disponível em: <https://www.youtube.com/watch?v=eU4pBkwh-VU>. Acesso em: 09 set. 2018.

BRASIL. Decreto $\mathbf{n}^{\mathbf{0}} \mathbf{4 . 8 8 7}$, de 20 de novembro de 2003. Disponível em: <http://www.planalto.gov.br/ccivil_03/decreto/2003/D4887.htm >.

BRUSH, Stephen B. (1996): Whose Knowledge, Whose Genes, Whose Rights? In: BRUSH, Stephen B.; STABINSKY, Doreen (eds.). Valuing Local Knowledg: Indigenous People and Intellectual Property Rights. Washington: Island Press. 
BUCHER, Stephanie. Der Schutz von genetischen Ressourcen und indigenem Wissen in Lateinamerika. Baden-Baden: Nomos, 2008.

BUTTERFIELD, Herbert. The origins of Modern Science. New York: The Macmillan Company, 1959.

CAG (2010): Comptroller of Auditor General. Report, New Delhi, n. 17, nov. 2010.

CAMPOS, Fernanda de Freitas. Antropofagia ritual dos povos Tupinambá nas cartas jesuíticas de meados do século XVI. 2013. 44f. Monografia (bacharelado em História) - Departamento de História do Instituto de Ciências Humanas, Universidade de Brasília, Brasília, 2013.

CARDOSO, Fernando Henrique; FALETTO, Enzo. $9^{\mathrm{a}}$ Ed. Dependência e desenvolvimento na América Latina. Rio de Janeiro: Civilização Brasileira, 2010.

CARNEIRO DA CUNHA, Manuela. Cultura com aspas e outros ensaios. São Paulo: Cosac Naif, 2009.

CARTA Maior. Acusação de biopirataria contra Natura expõe legislação falha. Disponível em:<http://cartamaior.com.br/?/Editoria/Meio-Ambiente/Acusacao-debiopirataria-contra-Natura-expoe-legislacao-falha/3/10549>. Acesso em: 11 jul. 2018. CASSIRER, Ernst. Was ist der Mensch? Versuch einer Philosophie der menschlichen Kultur. Disponível em: <www.abiunity.de>. Acesso em: 10 jul. 2018.

CBD (2011): UNEP/CBD/COP/11/7. Report of the Seventh Meeting of the Ad Hoc open-ended inter-sessional working group on Article 8 (j) and related provisions of the Convention on Biological Diversity. Hyderabad: CBD.

CERQUEIRA, Marcello. A Construção na História - Da Revolução Inglesa de 1640 à Crise do Leste Europeu. $2^{\mathrm{a}}$ ed. Rio de Janeiro: Revan, 2006.

CHAYTOR, Beatrice; CAMERON, James. O tratamento das questões ambientais no âmbito da Organização Mundial do Comércio. In: BERGESEN, H.O., PARMANN, G.; THOMMESSEN, O. B. (Orgs.) Yearbook of International Co-operation sobre Meio Ambiente e Desenvolvimento. Londres: Earthscan Press, 1999/2000.

COBO, Jose R. Martinez. Study of the Problem of Discrimination Against Indigenous Populations. United Nations, Economic and Social Council, 1984. Disponível em: <https:/www.un.org/development/desa/indigenouspeoples/publications/ 2014/09/martinez-cobo-study/>. Acesso: 22 out. 2018>. Acesso em: 12 jun. 2018.

COMPARATO, Fábio Konder. A Afirmação Histórica dos Direitos Humanos. $4^{\mathrm{a}}$ ed. São Paulo: Saraiva, 2005.

CONTI, Rafael Augusto de. História da filosofia dos direitos humanos. Disponível em: < http://www.rafaeldeconti.pro.br/Artigos/Historia-da-filosofia-dos-direitos-humanos>. Acesso em: 12 ago. 2018.

COPI, I.; COHEN, C. Introduction to logic. 8. ed. New York: Macmillan Publishing Company, 1990. 
COUTO, Hildo Honório do. Ecolinguística: estudo das relações entre língua e meio ambiente. Brasília: Thesaurus, 2007.

CRESPI, R. S. Patentes: um guia básico para Patenteamento em Biotecnologia. Cambridge: Cambridge University Press, 1988.

CUNHA, Manuela Carneiro da. Índios no Brasil: história, direitos e cidadania. São Paulo: Brasiliense, São Paulo, 1987.

CUNHA, Manuela Carneiro. Cultura com aspas e outros ensaios. São Paulo: Cosac Naify, 2010.

CUNNING, David. Descartes' Modal Metaphysics. In: The Stanford Encyclopedia of Philosophy, 2018.

DA CUNHA, Manuela Carneiro. Relações e dissensões entre saberes tradicionais e saber científico. Revista da USP, São Paulo, n.75, p.76-84, set./nov. 2007.

DAES. Protection of the Heritage of Indigenous People. United Nations. In: Documento ONU, E/CN. 4, Sub. 2, 1997/14: New York and Geneva, 1997.

DALLARI, Dalmo. Teoria Geral do Estado. 9a ed. São Paulo: Malheiros, 2012.

DALLARI, Dalmo. A Luta pelos Direitos Humanos. In: LOURENÇO, Maria Cecília Direitos Humanos em Dissertações e Teses da USP: 1934-1999. São Paulo: Universidade de São Paulo, 1999.

DAMODARAN, A.: Economics and Policy Implications of National Biodiversity Legislation. In: Economic and Political Weekly, v. 38, n; 49, p. 5.201-5.209, 2003.

DAVIS, Shelton H. Diversidade cultural e direitos dos povos indígenas. Mana, Rio de Janeiro, v. 14, no 2, p. 573, out./2008.

DEBBARMA, Sukhendu: An Assessment of the Implementation of the Indian Government's International Commitments on Traditional Forest-Related Knowledge from the Perspective of Indigenous Peoples. In: The International Alliance of Indigenous and Tribal Peoples of the Tropical Forests (eds.). Our Knowledge for Our Survival. Chiang Mai: IAITPTF/Centre for International Forestry Research, Indonesia, p. 225-245, 2006.

DESCARTES, R. O Mundo ou Tratado da Luz. São Paulo: Hedra, 2008.

DESCARTES, René. Discurso del método. Buenos Aires: Centro Editor de Cultura, 2006.

DESCARTES, René. Discurso do Método e as Paixões da Alma. Lisboa: Sá da Costa, 1984.

DIEGUES, A. C. O mito moderno da natureza intocada. São Paulo: HUCITEC; NAPAUB/USP, 2008. 
DO COUTO, Hildo Honório. Ecolinguística: estudo das relações entre língua e meio ambiente. Brasília: Thesaurus, 2007.

DOUZINAS, Costas. O fim dos Direitos Humanos. São Leopoldo: Unisinos, 2009.

DUPRAT, Deborah. Prefácio. In: SHIRAISHI NETO, Joaquim. (org.). Direito dos povos e das comunidades tradicionais no Brasil: declarações, convenções internacionais e dispositivos jurídicos definidores de uma política nacional. Manaus: UEA, 2007a.

DUSSEL, Enrique. Filosofia da libertação: crítica à ideologia da exclusão. $3^{\mathrm{a}}$ ed. São Paulo: Paulus, 2005.

DUSSEL, Enrique. Transmodernidad e Interculturalidad: Interpretación desde la Filosofia de la Liberación. México City: UAM-Iz., 2005.

DUTFIELD, Graham. A Critical Analysis of the Debate on Traditional Knowledge, Drug Discovery and Patent-Based Biopiracy. European Intellectual Property Review, n. 33, v. 4, p. 238-245, 2011.

DUTFIELD, Graham. Intellectual Property, Biogenetic Resources and Traditional Knowledge. London: Earthscan, 2004.

EASTWOOD, Lauren E. Resisting Dispossession: Indigenous Peoples, the World Bank and the Contested Terrain of Policy. New Global Studies, v. 5, n; 1, Article 1, 2011.

ESCOBAR, Arturo. O lugar da natureza e a natureza do lugar: globalização ou pósdesenvolvimento? In: LANDER, Edgar. A colonialidade do saber: eurocentrismo e ciências sociais. Buenos Aires: CLACSO, 2005.

EUROPEAN Parliament. European Parliament resolution of 15 January 2013 on development aspects of intellectual property rights on genetic resources: the impact on poverty reduction in developing countries, 2012.

EVA, Luiz Antonio Alves. O Fideísmo cético de Montaigne. Kriterion, Belo Horizonte, ano 33, n. 86, 8 dez. 1992, p. 42-59.

FACHIN, Melina Girardi. Fundamentos dos direitos humanos: teoria e práxis na cultura da tolerância. Rio de Janeiro: Renovar, 2009.

FANON, Frantz. Pele Negra, Máscaras Brancas. Salvador: EDUFBA, 2008.

FANON, Frantz. Pele negra, máscaras brancas. Trad.: Adriano Caldas. Rio de Janeiro: Sindicato nacional dos Editores e Livros, 1983, p. 90.

FARIÑAS DULCE, José María. La tensión del “pluralismo' desde la perspectiva filosófica intercultural. Derechos y Libertades: revista del Instituto Bartolomé de las Casas, v. VIII, p. 191-204, 2003.

FILHO, Calixto Salomão. Novo Estruturalismo Jurídico: Teoria do Direito. Revista dos Tribunais, RT926, Dez.2012. 
FIORILLO, Celso Antonio Pacheco. Curso de direito ambiental brasileiro. $11^{\mathrm{a}}$ Ed. São Paulo: Saraiva, 2010.

FISS, Owen. The Death of the Law. Cornell Law Review, vol. 72.

FORNET-BETANCOURT, Raúl. La filosofía intercultural frente a los desafíos de la globalización. Centro de Estudios y Actualización em Pensamiento Político, Descolonialidad e Interculturalidad - CIAPEDI/Universidad Nacional del Comahue.

FUNAI. Fundação Nacional do Índio. Disponível em: <http://www.funai.gov.br/index.php/servico-de-protecao-aos-indios-spi>. Acesso em: 4 out. 2018

GIACOIA Jr, Oswaldo. Sobre Direitos Humanos na Era da Biopolítica. Belo Horizonte, Kriterion: Revista de Filosofia, v. 49, nº 118, 2008.

GODDU, André. Reflections on the Origin of Copernicus's Cosmology. Journal for the History of Astronomy, v. 37, n. 1, p. 37-53, 2006.

GOTTING, Horst-Peter (2004): Biodiversitat und Patentrecht. GRURInt, n. 9, p. 731736, 2004.

GUDEMAN, Stephen. Sketches, Qualms, and Other Thoughts on Intellectual Property Rights. In: Brush, Stephen B./Stabinsky, Doreen (eds.). Valuing Local Knowledge: Indigenous People and Intellectual Property Rights. Washington: Island Press, 1996.

GUPTA, Anil K. et al. Mobilizing Grassroots' Technological Innovations and Traditional Knowledge, Values and Institutions: Articulating Social and Ethical Capital. Futures, v. 35, n. 9, p. 975-987, 2003.

HARVEY, David. Justice, Nature and the Geography of Difference. Cambridge: Blackwell, 1996.

HARVEY, David. The New Imperialism. Oxford: Oxford University Press, 2003.

HATHAWAY, David. A Biopirateria No Brasil. In: Sob o signo das bios. Reflexões no Brasil, n. 1, p. 39-49, 2004.

HAWKING, Stephen. Uma Breve História do Tempo: do Big Bang aos Buracos Negros. São Paulo: Rocco, 1988.

HEILBRON, John L. The Oxford Comparison to the History of Modern Science Cambridge: Oxford University Press, 2003.

HERRERA Joaquín Flores. Direitos humanos, interculturalidade e racionalidade da resistência. Direito e Democracia, v. 4, n. 2, jul./dez., p. 287-303, 2003.

HEYWOOD, V. H. (ed.) Avaliação da Biodiversidade. Cambridge: Cambridge University Press, 1995.

HEYWOOD, V. H. A diversidade da vida. Cambridge: Harvard University Press, 2012. 
HOBBES, Thomas. Leviathan, or the Matter, Forme, \& Power of a CommonWealth Ecclesiasticall and Civill. London: Penguin, 1985.

HÖFFE, Otfried. Derecho Intercultural. Barcelona: Gedisa, 2008.

INDIA, The Protection of Civil Rights Act, 1955. Disponível em: <http://tribal.nic.in/Content/act.aspx>. Acesso em: 12 jul. 2015.

INDIA. Censo Indiano Office of the Registrar General \& Census Commissioner. Disponível em: $<$ http://censusindia.gov.in/Census_And_You/scheduled_castes_and_sce duled_tribes.aspx>. Acesso em: 12 jun. 2018.

INDIA. National Tribal Policy (Draft), New Delhi: Ministry of Tribal Affairs. Government of India. The Scheduled Tribes (Recognition of Forest Rights) Bill, New Delhi, 2006.

INTERNATIONAL Labour Office. Indigenous people: living and working conditions of aboriginal populations in independent countries. Genebra: I.L.O., 1953.

JOBIM E SOUZA, S. Linguagem e ideologia: conversa com Bakhtin e Vygotsky. $2^{\text {a }}$ ed. São Paulo: Cortez, 2003.

KANT, Immanuel. Kritik der pratischen Vernunft. Frankfurt/Main: Suhrkamp, 1974.

KANT, Immanuel. Crítica da Razão Pura - Parte II. Lisboa: Calouste Gulbenkian, 2008.

KANT, Immanuel. Escritos Políticos. São Paulo: UNESP, 2005.

KANT, Immanuel. Grundlegung zur Metaphysik der Sitten. Frankfurt/Main: Suhrkamp, 1974

KAPUR, Shilpi; KIM, Sukkoo. British Colonial Institution and Economic Development in India. National Bureau of Economic Research, Cambridge, n. 2, v. 138, out. 2006.

KARANTH, Ullas K.; PRAVEEN, Bhargav. De-fragmenting Nature, Seminar, v. 552, ago. 2005.

KATO YAMAKAKE, Takeo Ángel [et al.]. Origen y diversificación del maíz: una revisión analítica. México: Universidad Nacional Autónoma de México, Comisión para el Conocimiento y Uso de la Biodiversidad, 2009. Disponível em: <http://www.biodiversidad.gob.mx/genes/pdf/origen_div_maiz.pdf >. Acesso em: jul. 2018.

KAUSHIK, Atul. Protecting Traditional Knowledge, Innovations and Practices: The Indian Experience. In: TWAROG, Sophia; KAPOOR, Promila (eds.). Protecting and Promoting Traditional Knowledge: Systems, National Experiences and International Dimensions. New York: United Nations, 2004.

KENNEDY, David. The International Human Rights Movement: Part of the Problem? Harvard H11111án Righ1sjo, n. I, v. 15, 2008. 
KERSTING, Wolfgang. O universalismo dos direitos humanos e a diversidade cultural. Fragmentos de Cultura, Goiânia, Universidade Católica de Goiás, v.12, n. ${ }^{\circ}$ especial, p. 9-27, mar. 2002.

KFFURI, Carolina [et al.] Antimalarial plants used by indigenous people of the Upper Rio Negro in Amazonas, Brazil. Journal of Ethnopharmacology, v. 178, p. 188-198, 2016.

KUNDNANI, A. Where do you want to go today? The rise of information capital. Race and Class, v. 40, p. 49-71, 1998-1999.

LAFER, Celso. A Reconstrução dos Direitos Humanos - Um Diálogo com o Pensamento de Hannah Arendt. São Paulo: Cia. das Letras, 1988.

LEELAKRISHNAN, P. Environmental Law Case Book. New Delhi: Lexis Nexis, 2005.

LÉVI-STRAUSS, Claude. O Pensamento Selvagem. São Paulo: Companhia Nacional, 1976.

LÉVI-STRAUSS, Claude. O pensamento selvagem. São Paulo: Edusp, 1970.

LÉVI-STRAUSS, Claude. O pensamento selvagem. São Paulo: Papirus Editora, 1989.

LLAIAH, Kancha. Post Hindu India: A Discouse in Dalit Bahujan, Socio-Spiritual and Scientific Revolution, SAGE, 2009. Disponível em: <https://books.google.com.br/books?id=DpSHAwAAQBAJ\&pg=PA3\&lpg=PA3\&dq= bramanic+culture\&source=bl\&ots=6wsIZ_05OO\&sig=z64Q8ETFlxIRG_8eLjheHyHM bk4\&hl=ptBR\&sa=X\&ved=0ahUKEwj1_saj1rrZAhWJWpAKHe6ABy0Q6AEIKDAA $\# \mathrm{v}=$ onepage $\& \mathrm{q}=$ bramanic\%20culture $\& \mathrm{f}=$ false $>$. Acesso em: 6 jun. 2018.

LOCKE, John. Political Essays. Cambridge: Mark Goldie, 2013.

LONDRES, Flavia et al. As sementes tradicionais dos Krahô: uma experiência de integração das estratégias on farm e ex situ de conservação de recursos genéticos. Rio de Janeiro: AS-PTA, 2014.

LUCAS, Douglas Cesar. Direitos Humanos e Interculturalidade: um diálogo entre a igualdade e a diferença. 2. ed. Ijuí: Unijuí, 2013.

LUCIANO, Gersem José dos Santos. Língua, educação e interculturalidade na perspectiva indígena. R. Educ. Públ. Cuiabá, v. 26, n. 62/1, p. 295-310, maio/ago. 2017.

MACHADO, Paulo Affonso Leme. Direito Ambiental Brasileiro. 11 ${ }^{\mathrm{a}}$ Edição, São Paulo: Malheiros Editores, 2003.

MACRAE, E. The development of Brazilian public policies on the religious use of ayahuasca. In: LABATE, B.; MACRAE, E (ed.). Ayahuasca, ritual and religion in Brasil. Londres: Equinox, 2010.

MAHONEY, Michael S. Matemática e física. In: GILLISPIE, Charles Coulston (Org.). Dicionário de Biografias Científicas. Rio de Janeiro: Contraponto, 2007. 
MALAYALI. Bio-Cultural Community Protocol of the Traditional Healers of the Malayali Tribes, United Nations Enviroment Programme Natural Justicee, Cape Town, 2009.

MALKKI, L. National Geographic: The Rooting of Peoples and the Territorialization of National Identity Among Scholars and Refugees. Cultural Anthropology, v. 7, n. 1, p. 24-44, fev. 1992.

MARQUES, Pâmela Marconatto. O Direito Internacional dos povos indígenas: ação e memória nativas reconstruindo a agenda internacional. Revista Jurídica da Presidência. Brasília, v. 12, n. 98., out. 2010/jan.2011.

MARTÍNEZ, Gregório Peces-Barba. Curso de Derechos Fundamentales: Teoría General. Madrid: Universidad Carlos III de Madrid, Boletín Oficial del Estado, 1999.

MARX, Karl. Crítica da filosofia do direito de Hegel. São Paulo: Boitempo, 2005.

MAY, Christopher; SELL, Susan. Intellectual Property Rights. A Critical History. London: Lynne Rienner, 2006.

MAZZUOLI, Valerio de Oliveira. Curso de Direito Internacional Público. $6^{\text {a }}$ ed. São Paulo: RT, 2012.

MEENAKSHI, J.V.; RAY, R.; SOUVIK, G. Estimates of Poverty for SC, ST and Female- Headed Households. Economic and Political Weekly, p. 2.748-54, 29 jul. 2000.

MELLO, Celso Antônio Bandeira de. Conteúdo jurídico do princípio da igualdade. $3^{\mathrm{a}}$ Ed. São Paulo: Malheiros Editores, 2014.

MENON, Ajit. Environmental Policy, Legislation and Construction of Social Nature. Economic and Political Weekly, v. 41, n. 3, p. 188-192, 21 Jan. 2000.

MENON, Ajit. State, Communities and the Forest Question in the Kolli Hills: A Study of the Political Economy of Decentralisation. PhD Thesis, Madras Institute of Development Studies, University of Madras, 2000.

MIGNOLO, Walter (ed.). Capitalismo y geopolítica del conocimiento: el eurocentrismo y la filosofía de la liberación en el debate intelectual contemporáneo. Buenos Aires: Ediciones del Signo, 2001.

MILL, John Stuart. Sobre a Liberdade. Rio de Janeiro: Nova Fronteira, 2011.

MILLS, Sherylle. Indigenous Music and the Law: An Analysis of National and International Legislation. Yearbook for Traditional Music, v. 28, p. 57-86, 1996.

MIRANDA, Ana Carolina Pires. Povos e Comunidades tradicionais: análise do processo de construção sociológica e jurídica da expressão. 2012. 162f. Dissertação (mestrado em Ciências Sociais) - Universidade Federal do Maranhão, São Luís, 2012. 
MISRA, Kamal K. Indigenous Environmental Knowledge Today: The Context and Relevance. In: MISRA, Kamal K.; BASA, Kishor K. (eds.). Traditional Knowledge in Contemporary Societies. Delhi: Challenges \& Opportunities, 2007.

MOHANTY Biswajit. A Field View. Seminar, v. 552, p. 30-34, ago. 2005.

MOHANTY, B. B. Land Distribution Among Scheduled Castes and Tribes. Economic and Political Weekly, v. 36, n. 40, p. 3.857-68, 6 out. 2001.

MÖLLER, Josué Emilio. A fundamentação ético-política dos direitos humanos. Curitiba: Juruá, 2009.

MÖLLER, Josué Emilio. A Justiça como equidade em John Rawls. Porto Alegre: Sergio Antonio Fabris, 2006.

MÖLLER, Josué Emilio. Cultura, globalização e direitos humanos. [Anais da] 5. Semana de Extensão, Pesquisa e Pós-Graduação do UniRitter, Porto Alegre.

MÖLLER, Josué Emilio. O construtivismo de John Rawls aplicado na fundamentação dos direitos humanos fundamentais. Direito e Democracia. Revista de Ciências Jurídicas da ULBRA, v. 7, n. ${ }^{\circ}$ 2, p. 291-313, 2006.

MOONEY, P. R. A Lei da Semente. Outro Desenvolvimento e Recursos Genéticos Vegetais. Diálogo de Desenvolvimento. Uppsala: Dag Hammarskjold Foundation, 1983.

MORAIS, José Luis Bolzan de. Direitos Humanos "Globais (universais)" de todos, em todos os lugares! In: PIOVESAN, Flávia (Coord.) Direitos Humanos, Globalização econômica e integração regional: desafios do Direito Constitucional Internacional. São Paulo: Max Limonad, 2002.

MUKHERJEE, Santanu. The Journey of Indian Patent Law Towards Trips Compliance. IIC 2, p. 125-50, 2004.

MUKUL. Tribal Areas: Transition to Self-Governance. Economic and Political Weekly, v. 32, n. 18, p. 928-29, maio 1997.

MUNDURUKU, Daniel. O caráter educativo do movimento indígena brasileiro 1970-1990. São Paulo: Paulinas, 2012.

NAIR, Janaki.Predatory Capitalism and Legalised Landgrab: Karnataka Land Reforms. Economic and Political Weekly, v. 31, n. 5, p. 251-52, 3 fev. 1996.

NATARA. Ucuuba, Ilha de Cotijuba. Disponível em: <https://www.youtube.com/watch?v=w2nPCEEkW6k>. Acesso em: 14 jun. 2018.

NATURA. Breu Branco. Disponível em: 〈https:/www.youtube.com/watch?v=eU4pBkwh-VU〉. Acesso em: 03 out. 2018.

NATURA. Perfume Priprioca. Disponível em: $<$ https://www.youtube.com/watch?v=rmJG9TcoZ3E >. Acesso em: 06. Jul. 2018.

O'GORMAN, Edmundo. A invenção da América: reflexão a respeito da estrutura histórica do Novo Mundo e do sentido do seu devir. São Paulo: Editora UNESP, 1992. 
OIT Aplicação da Convenção $n^{\circ} 169$ da OIT pelos tribunais nacionais e internacionais da América Latina, OIT, Programa de Promoção da Convenção nº 169 da OIT (PRO 169), (Genebra, 2009).

OIT. Convenção da OIT sobre Povos Indígenas e Tribais, 1989 (nº 169): Um Manual. Projeto para Promover a Política da OIT sobre Povos Indígenas e Tribais, 2000.

OIT. Direitos dos Povos Indígenas e Tribais na Prática: Um guia para a Convenção $\mathrm{n}^{\circ}$. 169 da OIT, OIT, Programa para Promover a Convenção no . 169 da OIT, Genebra, 2009.

OIT. Diretrizes para Combater o Trabalho Infantil entre Povos Indígenas e Tribais, OIT, IPEC e PRO 169, Genebra, 2006.

OIT. Eliminação da Discriminação contra Povos Indígenas e Tribais em Emprego e Ocupação: Um Guia para a Convenção nº. 111 da OIT, Genebra, 2007.

OIT. Nota de Orientação nº 7 da IFC sobre Povos Indígenas, Corporação Financeira Internacional, Genebra, 2007.

OIT. Observação Geral: Povos Indígenas e Tribais, Comitê de Peritos da OIT sobre a Aplicação de Convenções e Recomendações, Sessão 81, 2010. Conferência Internacional do Trabalho, 100ª sessão, 2011. Relatório III (1A).

OIT. Observação Geral: Povos Indígenas e Tribais, Comitê de Peritos da OIT sobre a Aplicação de Convenções e Recomendações, $79^{\mathrm{a}}$ sessão, 2008. Conferência Internacional do Trabalho, $98^{\text {a }}$ sessão, 2009. Relatório III (1A).

ORANGE, Claudia. An illustrated history of the Treaty of Waitangi. Erica revisada. Wellington: Bridget Williams Books, 2011.

ORANGE, Claudia. An illustrated history of the Treaty of Waitangi. Erica revisada. Wellington: Bridget Williams Books, 2011.

PAINE, Thomas. Senso Comum. In: WEFFORT, Francisco C. (Org.). Coleção os pensadores. 1.ed. São Paulo: Abril, 1973.

PAIVA, J. M. Transmitindo Cultura: A catequização dos índios do Brasil, 1.549-1.600.

Revista Diálogo Educacional, v. 1, n. 2, p. 1-22, 2000.

PANDHI, R.; ADVE, N. Endemic to Development: Police Killings in Kalinga Nagar. Economic and Political Weekly, v. 41, n. 3, 21 jan. 2006.

PANDIAN, Anand. Land Alienation in Tirunelvi District. Economic and Political Weekly, vol. 31, n. 51, p. 3291-94, 21 dez. 1996.

PANDIKUMAR, P. et al. Consensus of local knowledge on medicinal plants among traditional healers in Mayiladumparai block of Theni District, Tamil Nadu, India. Journal of Ethnopharmacology, v. 134, n. 2, p. 354-362, 2011.

PARIJS, Philippe van. O que é uma sociedade justa? São Paulo: Ática, 1997. 
PATHAK, Akhileshwar. Contested Domains: The State, Peasants and Forests in Contemporary India. New Delhi: Sage Publications, 1994.

PATHAK, Akhileshwar. Law, Strategies, Ideologies: Legislating Forests in Colonial India. Oxford: Oxford University Press, 2002.

PATHAK, Akhileshwar. State, Environment and Law. Economic and Political Weekly, v. 29, n. 50, p. 3138-141, 10 dez. 1994a.

PECES-BARBA MARTÍNEZ, Gregorio (Org.). Historia de losderechosfundamentales: tránsito a lamodernidad; siglos XVI y XVII. Madrid: Dykinson S. L., 2003.

Pessoa e reconhecimento: uma análise estrutural da dignidade da pessoa humana. Barzotto, Luis Fernando Revista brasileira de Filosofia, São Paulo, v. 58, n. 232, jan./jun. 2009. p. 78-106.

PIEDADE, Flávia Lordello. Biopirataria e direito ambiental: Estudo de caso do cupuaçu. 2008. 155f. Dissertação (mestrado em Ecologia de Agroecossistemas) Universidade de São Paulo, Piracicaba, 2008.

PIOVESAN, Flavia. Direitos humanos e justiça internacional: um estudo comparativo dos sistemas regionais europeu, interamericano e africano. $3^{\mathrm{a}} \mathrm{ed}$. São Paulo: Saraiva, 2012.

PIOVESAN, Flavia. Direitos humanos e o direito constitucional internacional. $15^{\mathrm{a}}$ Ed. Saraiva: São Paulo, 2015.

PIOVESAN, Flavia. Direitos Humanos: Desafios da Ordem Internacional Contemporânea. In: SCHILLING, Maria Luiza Bernardi Fiori (Org.). Caderno de Direito Constitucional, Escola da Magistratura do TRF da 4ª Região, 2006.

PIOVESAN, Flavia. A universalidade e a indivisibilidade dos direitos humanos: desafios e perspectivas. In: BALDI, César Augusto (Org.). Direitos humanos na sociedade cosmopolita. Rio de Janeiro: Renovar, 2004.

PIOVESAN, Flavia. Direitos humanos e o direito constitucional internacional. $7^{\mathrm{a}}$ ed. São Paulo: Saraiva, 2006.

PLATÃO. La République ou de la Justice. In: Philosophie Grècque. Paris: France Loisirs, 2000.

POSNER, Richard A. Problemas de Filosofia do Direito. São Paulo: Martins Fontes, 2007.

PREBISCH, Raul. Commercial policy in the underdeveloped countries. The American Economic Review, v. 49, n. 2, p. 251-273, 1959.

QUIJANO, Anibal. Colonialidade do poder, eurocentrismo e América Latina. In: LANDER, Edgardo (Org.) A colonialidade do saber: eurocentrismo e ciências sociais. Buenos Aires: Clacso, 2005. 
QUIJANO, Anibal. Colonialidade do poder, Eurocentrismo e América Latina. Buenos Aires: CLACSO, 2005.

QUIJANO, Aníbal. El fantasma del desarrollo en América Latina. Revista del CESLA, n. 1, p. 38-55, 2000.

QUIJANO, Aníbal; WALLERSTEIN, Immanuel. Americanity as a concept or the Americas in the modern world-system. International social science journal, v. 44, n. 4, p. 549-557, 1992.

RAMDAS, Sagari R. Whose access and whose benefit? The Nagoya Protocol and customary rights in India. In: ASHLEY, Holly; KENTON, Nicole; MILLIGAN, Angela (eds.). Participatory Learning and Action. London: International Institute for Environment and Development. Londres: IIED, 2012.

RANGARAJAN, Mahesh. Fire in the Forest. Economic and Political Weekly, v. 40, n. 47, p. 4888-90, 19 nov. 2005.

RAO, Siriginidi Subba. Indigenous Knowledge Organization: An Indian Scenario. International Journal of Information Management, v. 26, n. 3, p. 224-233, 2006.

RAUSTIALA, Kal; VICTOR, David G. The Regime Complex for Plant Genetic Resources. International Organization, v. 58, n. 2, p. 277-309, 2004.

RAWLS, John. O Direito dos povos. São Paulo: Martins Fontes, 2004.

REALE, Miguel. Filosofia do Direito. 17 ed. São Paulo: Saraiva, 1996.

REVISTA Globo rural. Contra biopirataria, projeto dá ao açaí o título de fruta nacional. Disponível em: <http://revistagloborural.globo.com/Revista/Common/0,EMI29315618077,00->. Acesso em: 12 jul. 2018.

ROCHA, Leonel Severo; BARZOTTO, Luis Fernando. Os Direitos Humanos como Direitos Subjetivos: da dogmática jurídica à ética. Revista da Procuradoria Geral do Estado, Porto Alegre, v.28, n.59 p. 137-175, jun.2004.

RODIS-LEWIS, G. A vida de Descartes e o desenvolvimento de sua filosofia. In: COTTINGHAM, J. (org.). Descartes. Aparecida: Ideias e Letras, 2009.

RODRÍGUEZ URIBES, José Manuel (Coord.). La Polémica Burke-Paine. In: Historia de los derechos fundamentales: el contexto social y cultural de los derechos, Los rasgos generales de evolución: siglo XVIII. Madrid: Dykinson S.L. t. 2, v. 1, p. 373417, 2001.

RODRÍGUEZ URIBES, José Manuel (Coord.). La Polémica Burke-Paine. In: Historia de los derechos fundamentales: el contexto social y cultural de losderechos. Los rasgos generales de evolución: siglo XVIII. Madrid: Dykinson S.L. t. 2, v. 1, p. 373417, 2001.

ROSENDAL, G. Kristin. Balancing Access and Benefit Sharing and Legal Protection of Innovations from Bioprospecting: Impacts on Conservation of Biodiversity. The Journal of Environmental Development, v. 15, n. 4, p. 428-447, 2006. 
ROUSSEAU, Jean-Jacques. LeDiscours sur l'Origine de l'Inégalité parmi les Hommes. Disponível em: <www.etudes-literaires.com>. Acesso em: 10 jun. 2018.

SAID, Edward. Culture and Imperialism. London: Vintage, 1994.

SAID, Edward. Orientalismo: o Oriente como invenção do Ocidente. Tradução: Rosaura Eichenberg. São Paulo: Companhia das Letras, 2007.

SANTILLI, Juliana. Socioambientalismo e Novos Direitos. São Paulo: Peirópolis, 2005.

SANTOS, Boaventura de Sousa. A gramática do tempo. São Paulo: Cortez Editora, 2006.

SANTOS, Boaventura de Sousa. A gramática do tempo: para uma nova cultura política. Lisboa: Cortez Editora, 2008.

SANTOS, Boaventura de Sousa. Entre Próspero e Caliban: colonialismo, póscolonialismo e inter-identidade. Novos Estudos Cebrap, n. 66, 2003.

SANTOS, Boaventura de Sousa. Epistemologias del Sur. Mexico: Siglo XXI, 2010.

SANTOS, Boaventura de Sousa. Reinventar a democracia. Lisboa: Gradiva, 1998.

SANTOS, Boaventura de Sousa; MENESES, Maria Paula; NUNES, João Arriscado. Opening Up the Canon of Knowledge and Recognition of Difference. In: SANTOS, Boaventura de Santos (ed.). Another Knowledge is Possible: Beyond Northern Epistemologies. Londres, 2007. Disponível em: <https://www.ces.uc.pt/publicacoes/res/pdfs/IntrodBioPort.pdf $>$. Acesso: 12 ago. 2018.

SANTOS, Walter da Silva. Refração, as Velocidades da Luz e Metamateriais. 2010. 199f. Dissertação (mestrado em Ensino de Física) - Universidade Federal do Rio de Janeiro, Rio de Janeiro, 2010.

SARLET, Ingo Wolfgang. A Eficácia dos Direitos Fundamentais. Disponível em:< www.mprj.mp.br>. Acesso em: 11 set. 2018.

SARLET, Ingo Wolfgang. Dignidade da Pessoa Humana e Direito Fundamentais na Constituição de 1988. Porto Alegre: Livraria do Advogado, 2004.

SCALCO, Pedro. Uma breve análise da fundamentação dos direitos humanos: universalismo e/ou relativismo cultural. RT:v., São Paulo, v. 98, n. 890, p. 69-79, dez. 2009.

SCORSATO, Simone Maria. Hospitalidade: o desafio das populações de pescadores que se transformam em fornecedores de serviços turísticos. Revista Hospitalidade, São Paulo, ano III, n. 2, p. 77-89, 2. sem. 2006.

SEMINARIST. The Conservation Conundrum. Seminar, v. 552, p. 55-58, ago. 2005.

SENGUPTA, Nirmal. Reappraising Tribal Movement (part II). Economic and Political Weekly, v. 23, n. 20, p. 1.003-05, 14 maio 1998. 
SEYFERTH, Giralda. Colonização, imigração e a questão racial no Brasil. Revista USP, São Paulo, n. 53, p. 117-149, mar. maio 2002.

SHARMA, Devinder. Selling Biodiversity: Benefit Sharing Is a Dead Concept. In: KOHLI, Kanchi (ed.). Understanding the Biological Diversity Act 2002. London : GRAIN/IIED, 2006.

SHETH, Alpha. et. al. Effects of the December 2004 Indian Ocean Tsunami on the Indian Mainland. Earthquake Spectra, v. 22, n. S3, p. S435-S473, 2006.

SHETH, Alpha. et. al. Effects of the December 2004 Indian Ocean Tsunami. Effects of the December 2004 Indian Ocean Tsunami on the Indian Mainland, autores Alpa Sheth, Snigdha Sanyal, Arvind Jaiswal, e Prathibha Gandhid. Disponível em:

http://www.iitk.ac.in/nicee/RP/2006_Effect_EQSpectra.pdf

SHIRAISHI NETO, Joaquim (Org.). Direito dos povos e das comunidades tradicionais no Brasil: declarações, convenções internacionais e dispositivos jurídicos definidores de uma política nacional. Manaus: UEA, 2007.

SHIVA, Vandana. Protect or Plunder? Understanding Intellectual Property Rights. London: Zed Books, 2001.

SHIVA, Vandana. Staying alive: Women, ecology and survival in India. Nova Delhi: Kali for Women, 1988.

SILVA, Virgílio Afonso da. O conteúdo essencial dos direitos fundamentais e a eficácia das normas constitucionais. Revista de Direito do Estado, p. 23-51, 2006.

SINGH, Satyajit, Taming the Waters: The Political Economy of Large Dams in India. Delhi: Oxford University Press, 1997.

SINGH, Tavleen.Lies About Tribal Rights. Seminar, v. 552, ago. 2005.

SIQUEIRA, Dirceu Pereira; PICCIRILLO, Miguel Belinati. Direitos fundamentais: a evolução histórica dos direitos humanos, um longo caminho. Disponível em: <www.ambito-juridico-leitura\&artigo_id=5414>. Acesso em: 12 jun. 2018.

SMITH, Donald B. Deskaheh. In: COOK, Ramsay; BÉLANGER, Réal. Dictionary of Canadian Biography. XV (1921-1930) (online ed.). University of Toronto Press, 2005.

SOUZA, Maria das Graças de. Ilustração e História - O Pensamento sobre a História no Iluminismo Francês. São Paulo: Discurso, 2001.

SPIVAK, Gayatri Chakravorty. In other worlds: Essays in cultural politics. New Yorke: Routledge, 2012.

STRECK, Lenio Luiz. (Org.). Anuário do Programa de Pós-Graduação em Direito: mestrado e doutorado. São Leopoldo: Editora Unisino, 2004.

STRECK, Lenio Luiz. (Org.). Globalização, direito cosmopolítico e direitos humanos. Revista do Instituto de Hermenêutica Jurídica, v.1, n. 4, p. 411-430, 2006. 
STRECK, Lenio Luiz. (Org.). O Direito no século XXI: desafios epistemológicos. Revista do Instituto de Hermenêutica Jurídica, v. 1, n. 3, p. 279-302, 2005.

STRECK, Lenio Luiz. (Org.). O fetiche dos direitos humanos e outros temas. 2. ed. Porto Alegre: Livraria do Advogado, 2013.

SUBRAMANIUM, C. Subramaniam, The New Strategy in Indian Agriculture: The First Decade and After. New Delhi: Vikas Publishing House, 1979.

TAYLOR, Charles. et. al. Multiculturalismo - examinando a política do reconhecimento. Princeton: UniversityPress, 1994.

TEIXEIRA, Vanessa Corsetti Gonçalves. Interculturalidade, direito e direitos indígenas. 2014. 236f. Tese (doutorado em Direito) - Faculdade de Direito, Universidade de São Paulo, São Paulo, 2014.

TEIXEIRA, Vanessa Corsetti Gonçalves. Interculturalidade, direito e direitos indígenas. 236f. 2014. Tese (doutorado em Direito), Faculdade de Direito, Universidade de São Paulo, São Paulo, 2014.

TEIXEIRA, Vanessa Corsetti Gonçalves. Interculturalidade, direito e direitos indígenas. 2014. 236f. Tese (doutorado em Filosofia e Teoria Geral do Direito) Faculdade de Direito, Universidade de São Paulo, São Paulo, 2014.

TEIXEIRA. O. S., CORDEIRO. R. Q. Educação jesuíta: Objetivo metodologia e conteúdo nos aldeamentos indígenas do Brasil colônia. Mneme - Revista de Humanidades, Caicó, v. 9. n. 24, p. 1-6, set./out. 2008.

The Indian Independence Act, 1947,

The Government of India Act, 1935.

THOMAS, V. (Ed.). Ocupações Tradicionais de Povos Indígenas e Tribais: Emergentes, Projeto para Promover a Política da OIT sobre Povos Indígenas e Tribais (PRO 169), Genebra, 2000.

THOMPSON, Mary C.; BARUAH, Manali; CARR, Edward R. Seeing Redd+ as a Project of Environmental Governance by Environmental Sciences. Environmental Science Policy, v. 14, n. 2, p. 100-110, 2011.

TORRES, Ricardo Lobo (Org.). Legitimação dos direitos humanos. Rio de Janeiro: Renovar, 2002.

TORRES, Ricardo Lobo (Org.). Legitimação dos direitos humanos. Rio de Janeiro: Renovar, 2002.

TRENTIN, Lorivan Antônio Fontoura. A Importância do Constitucionalismo na Realização dos Direitos Fundamentais. 2003. F 10. Dissertação (mestrado em direitos humanos) - UNISINOS, São Paulo, 2003. 
TRINDADE, Antônio Augusto Cançado. Tratado de Direito Internacional dos Direitos Humanos - Volume II. Porto Alegre: Sergio Fabris Editor, 1999.

UNITED Nations. UN Declaration of Indigenous Rights. Publicado em 2007. Disponível em: <http://www. un.org/esa/socdev/unpfii/documents/DRIPS_en.pdf>. Acesso em: 24 set. 2018.

UPADHYAY, Sanjay. Tribal Self-Rule Law and Common Property Resources in Scheduled Areas of India: A New Paradigm Shift or Another Ineffective Sop? The Commons in an Age of Global Transition: Challenges, Risks and Opportunities, hosted by the Instituto de Investigaciones Sociales, Universidad Nacional Autónoma de Mexico, Oaxaca, Mexico, p. 9-13, ago. 2004.

UPADHYAY, Videh, 2001, Forests, People and Courts: Utilising Legal Spaces. Economic and Political Weekly, v. 35, n.43/44. São Paulo: Cortez, 2006.

VANDERGEEST, Peter; NANCY, Peluso, Territorialization and State Power in Thailand. Theory and Practice, n. 24, p. 385-426, 1995.

VASCONCELOS, V.V. A Crítica da Razão na Apologia de Raymond Sebond, de Montaigne. Belo Horizonte: Universidade Federal de Minas Gerais, 2004.

VENKATARAMAN, K.; LATHA, Swana S. Intellectual Property Rights, Traditional Knowledge and Biodiversity of India. Journal of Intellectual Property Rights, v. 13. n 7, p. 326-335, 2008.

VIDO, Elisabete. Prática empresarial: Coleção Prática Forense - Vol. 5. $5^{\mathrm{a}}$ Ed. São Paulo: Revista dos Tribunais, 2014.

VILLARES, Luiz Fernando. Direito e povos indígenas. Curitiba: Juruá, 2009.

VISVANATHAN, Shiv. Between Cosmology and System: The Heuristics of a Dissenting Imagination. Disponível em: <http://www.arvindguptatoys.com/arvindgupta/cvs-shiv.pdf>. Acesso em: 14 ago. 2018.

VITORELLI, Edilson. Estatuto da Igualdade Racial e Comunidades Quilombolas. Salvador: Editora Juspodivm, 2012.

VON SCHELLING, Friedrich Wilhelm Joseph. On the History of Modern Philosophy. Cambridge: University Press, 2012.

VYGOTSKY, L.S. Psicologia Pedagógica. Porto Alegre: Artmed, 2003.

WALLERSTEIN, Immanuel. O universalismo europeu. São Paulo: Boitempo, 2007.

WALlERSTEIN, Immanuel. The Modern World System: Capitalist Agriculture and the Origins of the European World Economy in the Sixteenth Century. Nova Iorque: Academic Press, 1974.

WIPO-IGC. Elements of a Sui Generis System for the Protection of Traditional Knowledge. Out. 2002. Disponível em: <www.wipo.int/documents/ en/meetings/2002/igc/pdf/grtkf_ic_4_8.pdf>. Acesso em: 11 ago. 2018. 
WIPO-IGC. Inventory of Traditional Knowledge-Related Periodicals. Abr. 2002. Disponível em: <www.wipo.int/documents/en/meetings/2002/igc/pdf/grtkfic3_5.pdf>. Acesso em: 11 ago. 2018.

WIPO-IGC. The Protection of Traditional Knowledge: Revised Objectives and Principles. Abr. 2005. Disponível em: www.wipo.int/edocs/ mdocs/tk/en/wipo_grtkf_ic_8/wipo_grtkf_ic_8_5.doc>. Acesso em: 11 ago. 2018.

WTO. Uruguay Round Agreement: TRIPS - Trade-Related Aspects of Intellectual Property Rights. Disponível em: <http://www.wto.org/english/docs_e/legal_e/27trips_01_e.htm, 15.4.2013>. Acesso em: 23 set. 2018.

ZELLER, Christian. From the gene to the globe: Extracting rents based on intellectual property monopolies. Review of International Political Economy, v. 15, n. 1, p. 86$115,2008$.

ZILSEL, Edgar; FLECK, Christian. The Social Origins of Modern Science. In: History of Philosophy of Science. Dordrecht: Springer, 2002.

ZINGANO, Marco. Estudos de Ética Antiga. 1ª ed. São Paulo: Discurso, 2007. 